NASA Technical Memorandum 4745

\title{
Development and Flight Test of an Augmented Thrust-Only Flight Control System on an MD-11 Transport Airplane
}

Frank W. Burcham, Jr., Trindel A. Maine, John J. Burken, and Drew Pappas

July 1996

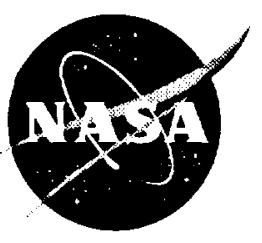


NASA Technical Memorandum 4745

\section{Development and Flight Test of an Augmented Thrust-Only Flight Control System on an MD-11 Transport Airplane}

Frank W. Burcham, Jr., Trindel A. Maine, and John J. Burken Dryden Flight Research Center Edwards, California

Drew Pappas

McDonnell Douglas Aerospace

Long Beach, California

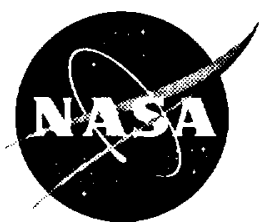

National Aeronautics and

Space Administration

Office of Management

Scientific and Technical

Information Program

1996 



\title{
DEVELOPMENT AND FLIGHT TEST OF AN AUGMENTED THRUST-ONLY FLIGHT CONTROL SYSTEM ON AN MD-11 TRANSPORT AIRPLANE
}

\author{
Frank W. Burcham Jr., \\ Trindel A. Maine ${ }^{\dagger}$, John J. Burken ${ }^{\dagger}$ \\ NASA Dryden Flight Research Center \\ Edwards, California \\ Drew Pappas ${ }^{\ddagger}$ \\ McDonnell Douglas Aerospace \\ Long Beach, California
}

\begin{abstract}
$\underline{\text { Abstract }}$
An emergency flight control system using only engine thrust, called Propulsion-Controlled Aircraft (PCA), has been developed and flight tested on an MD-11 airplane. In this thrust-only control system, pilot flightpath and track commands and aircraft feedback parameters are used to control the throttles. The PCA system was installed on the MD-11 airplane using software modifications to existing computers. Flight test results show that the PCA system can be used to fly to an airport and safely land a transport airplane with an inoperative flight control system. In up-and-away operation, the PCA system served as an acceptable autopilot capable of extended flight over a range of speeds and altitudes. The PCA approaches, go-arounds, and three landings without the use of any normal flight controls have been demonstrated, including instrument landing system-coupled hands-off landings. The PCA operation was used to recover from an upset condition. In addition, PCA was tested at altitude with all three hydraulic systems turned off. This paper reviews the principles of throttles-only flight control; describes the MD- 11 airplane and systems; and discusses PCA system development, operation, flight testing, and pilot comments.
\end{abstract}

"Chief, Propulsion Branch. Associate Fellow AIAA

${ }^{\dagger}$ Aerospace Engineer

${ }^{\ddagger}$ PCA Program Manager

Copyright (C) 1996 by the American Institute of Aeronautics and Astronautics, Inc. No copyright is asserted in the United States under Title 17, U.S. Code. The U.S. Government has a royalty-free license to exercise all rights under the copyright claimed herein for Governmental purposes. All other rights are reserved by the copyright owner.

\section{$\underline{\text { Nomenclature }}$}

AGL above ground level, $\mathrm{ft}$

c.g. center of gravity, percent of mean aerodynamic chord (fig. 1)

LSAS Iongitudinal stability augmentation system

EPR engine pressure ratio

FADEC full-authority digital engine control

FCC flight control computer

FCP flight control panel on cockpit glareshield

FDS flight deck simulator

FPA flightpath angle, deg

GW gross weight, lb

HDG heading

IAS indicated airspeed, $\mathrm{kn}$

ILS instrument landing system

MCDU multifunction control and display unit

ND navigation display

PCA propulsion-controlled aircraft

PFD primary flight display

TRK track angle, deg

$\mathrm{V} / \mathrm{S} \quad$ vertical speed, $\mathrm{ft} / \mathrm{min}$

\section{Introduction}

In the last 20 years, pilots of B-747, B-52 (The Boeing Company, Seattle, Washington); L-1011 (Lockheed Martin, Palmdale, California); C-5A (Lockheed Martin, Marietta, Georgia); and DC-10 
(McDonnell Douglas Aerospace (MDA), Long Beach, California) aircraft have experienced major flight control system failures and have had to use throttles for emergency flight control. In the majority of cases, a crash resulted; the B-747, DC-10, and C-5A crashes claimed over 1200 lives. $^{1}$

To investigate the use of engine thrust for emergency flight control, the National Aeronautics and Space Administration, Dryden Flight Research Center (DFRC), Edwards, California, conducted flight, ground simulator, and analytical studies. One objective was to determine the degree of control available with manual manipulation of engine throttles for various classes of airplanes. Tests in simulation have included B-720, B-747, B-727, MD-11, C-402, C-17, F-18, and F-15 airplanes. In addition, B-747, B-777, MD-11, T-39, Lear 24, F-18, F-15, T-38, and PA-30 airplanes were flight tested. The pilots used differential throttle control to generate sideslip, which through the dihedral effect results in roll. Symmetric throttle inputs were also used to control flightpath. This objective has shown sufficient control capability for all tested airplanes to maintain gross control; flightpath and track angle may be controlled to within a few degrees. For all airplanes tested, it is exceedingly difficult to make a safe runway landing using manual throttles-only control $^{2}$ because of problems in controlling the phugoid and dutch roll modes, slow engine response, and weak control moments.

To provide safe landing capability, DFRC engineers and pilots conceived and developed a system that uses only augmented engine thrust, called PropulsionControlled Aircraft (PCA). A PCA system uses pilot flightpath inputs and airplane sensor feedback parameters to provide appropriate engine thrust commands for emergency flight control. This augmented system was first evaluated on a B-720 transport airplane simulation. ${ }^{3}$

Later, simulation studies and flight tests were conducted on an F-15 airplane to investigate throttlesonly control ${ }^{4}$ and to investigate the in-flight performance of an augmented PCA system. ${ }^{1}$ The PCA system flight hardware and software were developed and implemented by MDA. Flight testing included landings using PCA control. ${ }^{5}$ The PCA technology was also successfully evaluated using a simulation of a conceptual megatransport. ${ }^{\circ}$ Another major simulation study has been conducted at NASA Ames Research Center (ARC), Moffett Field, California, using the advanced concepts fight simulatc. Over 400 simulated
PCA landings have been flown by more than 20 pilots,' and a PCA system has been evaluated on a B-747 simulation.

As a follow-on to the F-15 PCA research, MDA and DFRC developed and tested a concept demonstration PCA system for the MD-11 transport airplane. An intermediate objective was to demonstrate controlled up-and-away flight over a flight envelope from 150 to $250 \mathrm{kn}$ below $15,000 \mathrm{ft}$. Another was to make low approaches to a runway that could have been continued to a survivable landing. The goal was to make actual PCA landings. To make the PCA demonstration apply to the large number of transports with two wing-mounted engines, the MD-11 PCA system primarily used only the wing engines. The PCA system used only software changes to existing digital systems on the MD-11. In over $30 \mathrm{hr}$ of testing, the PCA system exceeded the objectives, served as a very acceptable autopilot, and performed landings without using any flight controls. ${ }^{8}$

Later tests studied PCA operation over the full fight envelope, in upset conditions, with the hydraulics turned off, and coupled to an instrument landing system (ILS) for hands-off landings. Sixteen pilots flew PCA demonstration flights. Analysis of the control system design and performance is given in reference 9 . The longitudinal control details are given in reference 10 . Details of the hardware architecture, software development, and testing are given in reference 11.

This paper describes the MD-11 airplane, principles of throttles-only flight control, and throttles-only control modes. The PCA system implementation, operation, development, and test are discussed. In addition, control laws, pilot comments, flight test results, and recommended future PCA applications are presented.

\section{Airplane Description}

The MD-11 airplane is a large, long-range, threeengine, wide-body transport. This $202 \mathrm{ft}$ long airplane has a wingspan of $170 \mathrm{ft}$ and a maximum takeoff gross weight of $618,000 \mathrm{lb}$ (fig. 1). The test airplane, ship 560, was configured for flight test and had no interior furnishings.

\section{Flight Control Systems}

The MD-11 airplane has a mechanical flight control system with irreversible hydraulically powered actuators. Three systems provide hydraulic power. Essential control functions may be maintained on any one of these three systems. Dual elevators provide pitch control. A hydraulic jackscrew-actuated horizontal 

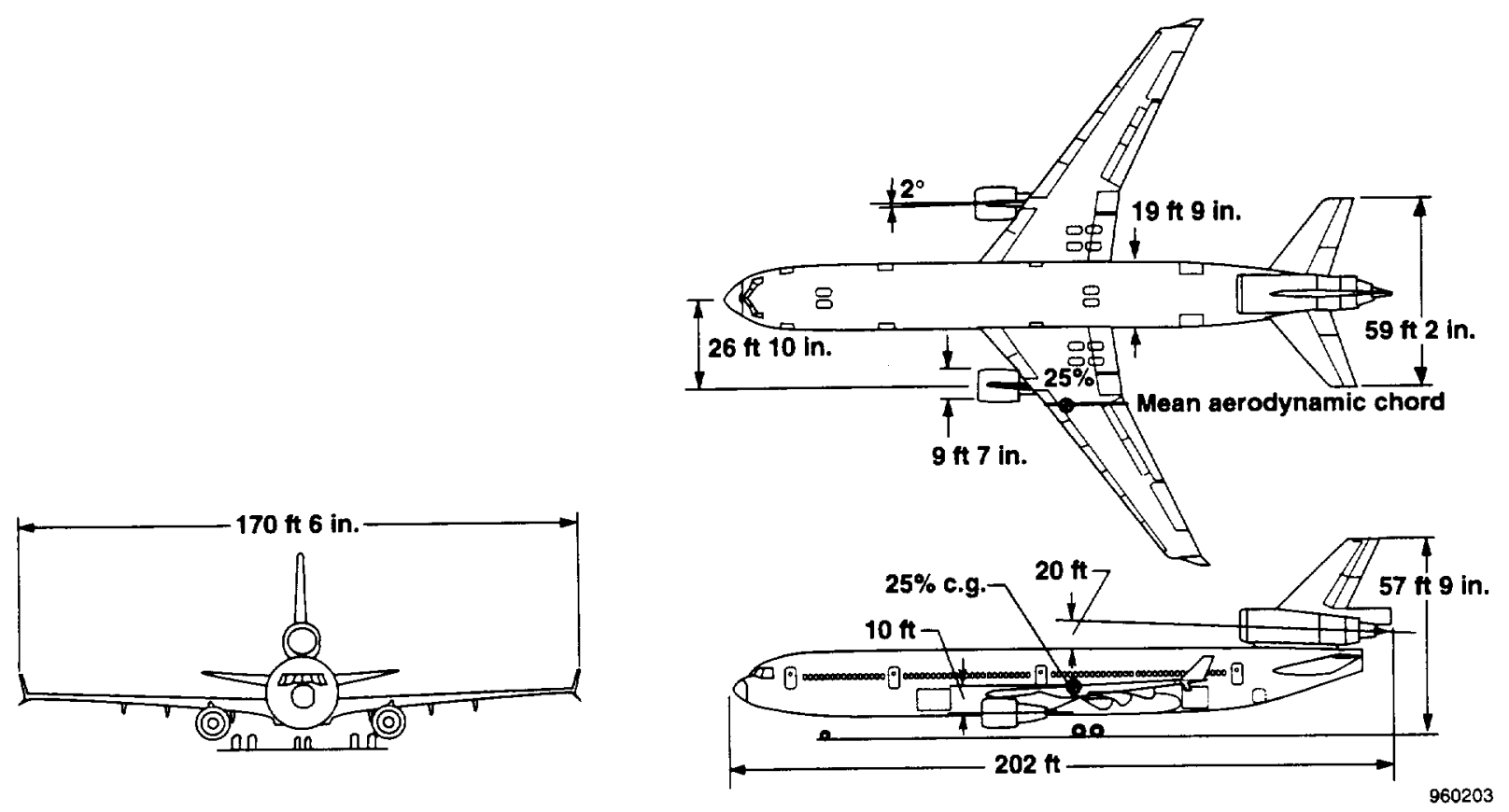

(a) Three-view drawing.

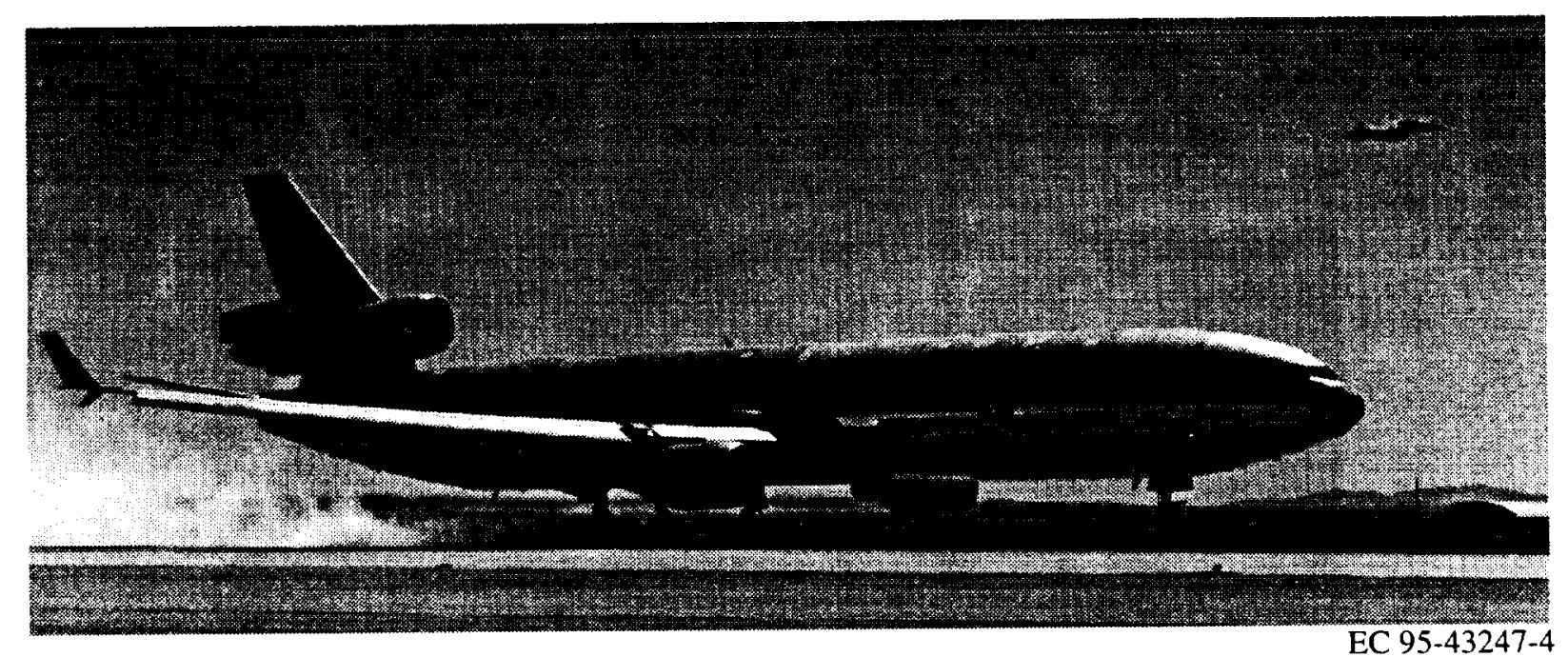

(b) Photograph.

Figure 1. The MD-11 airplane.

stabilizer provides pitch trim. Inboard and outboard ailerons supplemented by wing spoilers provide roll control. Dual rudders provide yaw control. Hydraulic actuated leading- and trailing-edge flaps are provided. In case of hydraulic system failure, the stabilizer would effectively lock, the flaps would drift up, and other surfaces would float.
The standard MD-11 airplane is equipped with an advanced cockpit. Figure 2(a) shows the electronic displays on the main panel, glareshield control panel, and automated systems management located on the overhead panel. The mechanical flight control system of an MD-11 airplane has longitudinal stability augmented by a longitudinal stability augmentation system (LSAS) 
and a dual yaw damper. The autoflight system (AFS) includes autopilot, autothrottle and speed control, stall warning, turn coordination, flap limiting, windshear detection, and other features. A flight management system integrates the autopilot navigation, and autoland functions. The crew communicates with the flight management system using the multifunction control and display units (MCDU) located on the center pedestal.

Figure 2(b) shows the autoflight system crew interface and display. The glareshield flight control panel (FCP) includes a thumbwheel for selecting flightpath angle (FPA) or vertical speed (V/S). A heading or track knob is used to select the desired heading or track. The primary flight display (PFD) shows the selected and actual flightpath, heading, or track. These data are shown on the navigation display (ND) and on the PFD. A speed selection knob normally commands the autothrottle speed and Mach number hold.

\section{Engines}

The MD-11 airplane tested was powered by three high-bypass ratio Pratt \& Whitney (East Hartford, Connecticut) 4460 turbofan engines in the $60,000-\mathrm{lb}$ thrust class. Two engines are mounted in underwing pods, $10 \mathrm{ft}$ below and $26 \mathrm{ft} 10 \mathrm{in}$. outboard of the nominal center of gravity (c.g.). The third engine is located at the base of the vertical tail $20 \mathrm{ft}$ above the vertical c.g. and inclined $2.5^{\circ}$ nose-up. These engines have full-authority digital engine control (FADEC) systems. The crew normally controls the engines with electronic throttles which command a power setting based on engine pressure ratio (EPR). The EPR varies from just below 1.0 at idle to approximately 1.6 at maximum power; thus, each 0.1 EPR is approximately $10,000 \mathrm{lb}$ of thrust.

The FADEC systems normally accept small (approximately \pm 5 percent) EPR trim commands from the flight management system to closely maintain engine limits or thrust settings and eliminate the need for throttle stagger to match engines to a given EPR. As is typical for high-bypass turbofans, thrust response near idle power is initially slow. Once thrust reaches approximately 20 percent, the thrust response improves dramatically. In the midthrust range, thrust has a time constant of approximately $0.5 \mathrm{sec}$. Thrust decay also shows similar nonlinear effects.

\section{Fuel System}

The MD-11 airplane is equipped with fuel tanks located in the wings, center fuselage, and horizontal tail. Maximum fuel quantity is $259,000 \mathrm{lb}$. Fuel may be

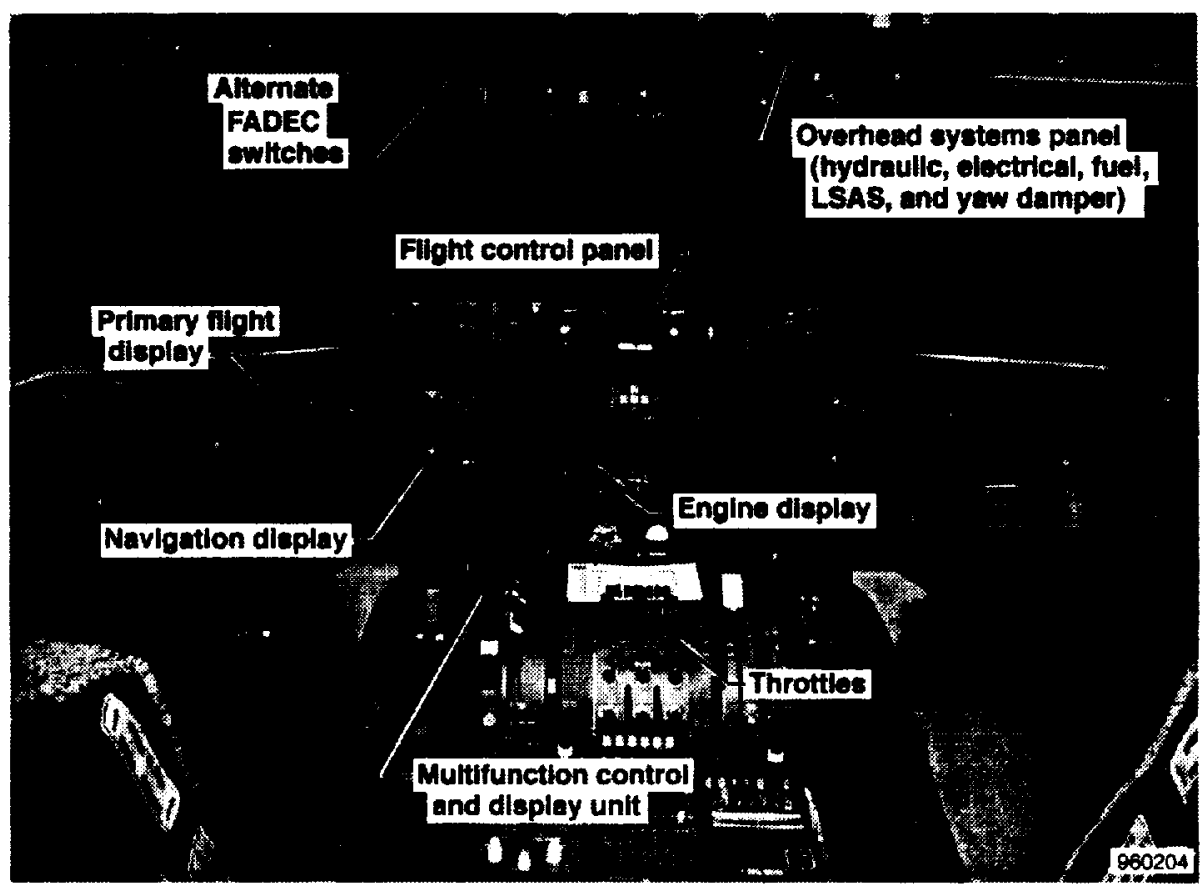

(a) Cockpit.

Figure 2. The MD-11 cockpit and autoflight system. 


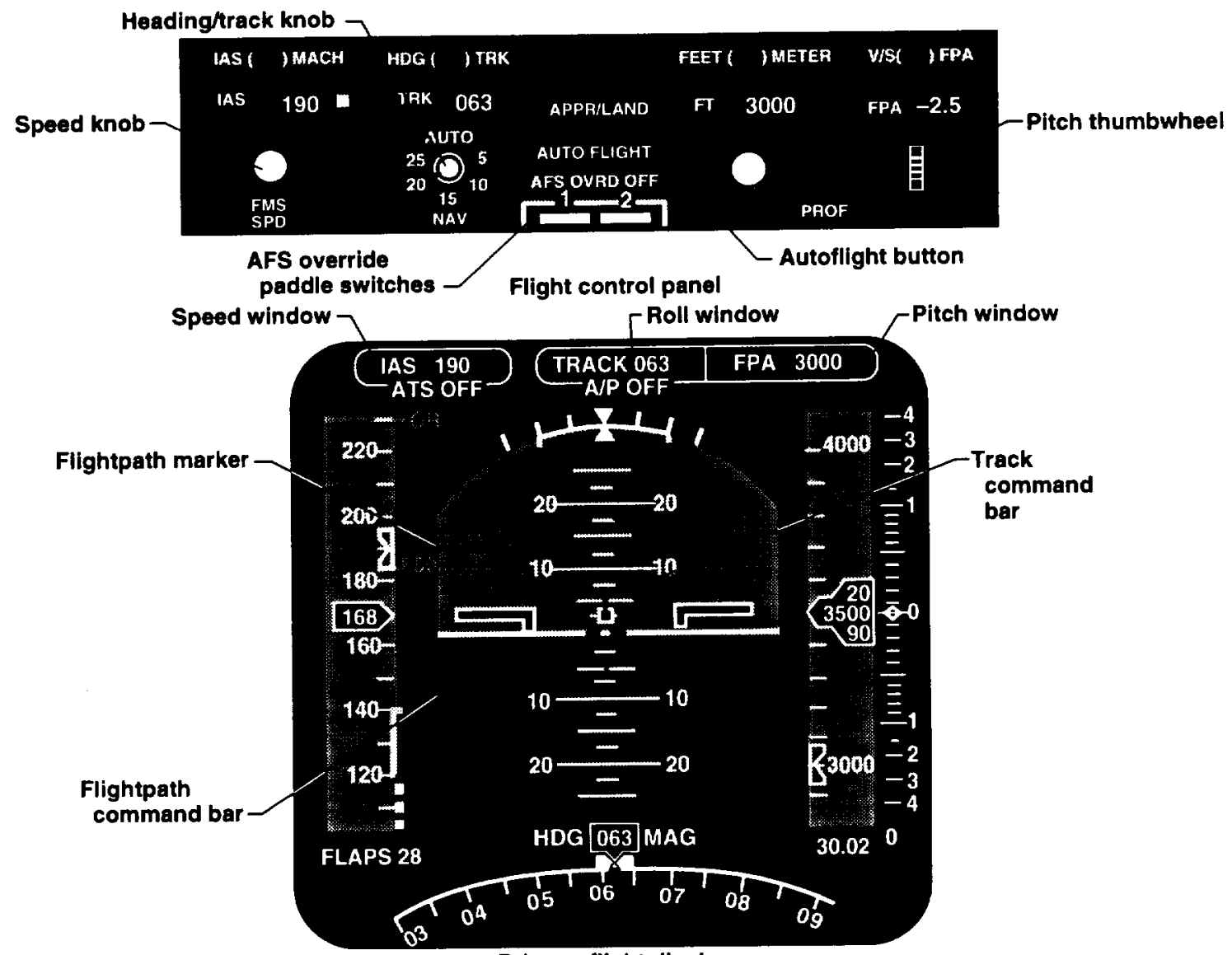

Primary flight display

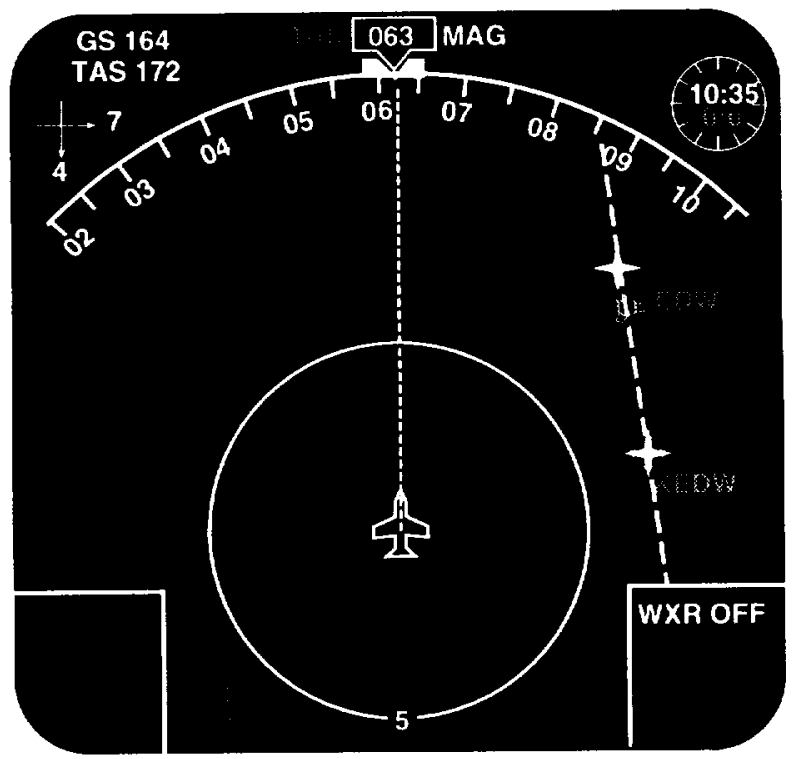

Navigation display

(b) Autoflight system crew interface and display.

Figure 2. Concluded. 
transferred to the tail tank, which can move the c.g. aft up to 10 percent from nominal. Fuel may be dumped down to a total of $40,000 \mathrm{lb}$.

\section{Weight and Center of Gravity}

With a full payload of $122,700 \mathrm{lb}$, the MD-11 airplane has zero-fuel weight of $400,000 \mathrm{lb}$. Maximum gross weight (GW) is $618,000 \mathrm{lb}$, and maximum landing weight is $430,000 \mathrm{lb}$. The longitudinal c.g. is given in percent mean aerodynamic chord (fig. 1). At cruise altitude, the fuel management system transfers fuel to the tail tank that maintains the c.g. at an airline selectable aft limit of approximately 32 percent. For takeoff and landing, the c.g. is normally approximately 20 to 24 percent. The forward limit is 12 percent.

\section{Landing Gear}

The MD-11 airplane is equipped with a steerable nosewheel and three main landing gears. The gear may be lowered with an alternate system independent of the hydraulic system. Limited braking may be obtained with inoperative hydraulic systems using brake accumulators.

\section{Instrumentation}

The test MD-11 airplane was equipped with a large data acquisition system that can display and record several thousand parameters from the digital data buses. This system included airdata, engine, and inertial parameters as well as flight control and PCA systems parameters. A real-time plotting and hardcopy capability was also available. Cameras were installed in the cockpit to record the pilot's out-the-window view. Equipment was also installed to record communications and pilot comments.

\section{MD-11 Simulation}

The MD-11 flight deck simulator (FDS) used for the majority of the MD-11 PCA research was a highfidelity, fixed-based, piloted simulator with a great deal of actual flight hardware in the cockpit. systems, and electronics. This simulation included a projection digital display system capable of displaying Long Beach, Edwards, and other Southern California visual scenes. Scenes from Yuma, Arizona, can also be displayed. In addition, an off-line version of the full MD-11 simulation was hosted on an IBM mainframe computer. This nonlinear simulation was used for control system development and evaluation.

For fight control system and engine control system integration testing, the MD-11 bench simulation was used. This simulation allowed actual PCA software in Flight Control Computers (FCC) and one FADEC to operate through the data buses and used a database similar to the FDS. Pilot inputs could be simulated with a joystick interface.

\section{Principles of Throttles-Only Flight Control}

This section describes the principles of throttles-only flight control. Examples are for the MD-11 airplane.

\section{Lateral-Directional}

Differential thrust generates sideslip which, through the dihedral effect, results in the airplane rolling to a desired bank angle which results in a turn and change in aircraft heading. Figure 3 shows an open-loop throttle step response for the MD- 11 airplane at $220 \mathrm{kn}$. The $10^{\circ}$ throttle split results in approximately $20,000 \mathrm{lb}$ of differential thrust and a roll rate averaging $1.5 \mathrm{deg} / \mathrm{sec}$. Note that the EPR lags the throttle by approximately $1 \mathrm{sec}$, and the roll rate lags the yaw rate. A lightly damped dutch roll mode is excited by this throttle step. Full differential thrust for the MD- 11 airplane at a speed of $150 \mathrm{kn}$ yields a peak roll rate of approximately $8 \mathrm{deg} / \mathrm{sec}$.

\section{Longitudinal}

Pitch control caused by throttle changes is more complex than lateral-directional control. Several effects occur. These effects include flightpath angle changes caused by speed stability; pitching moment resulting from thrust line offset, and flightpath angle changes because of vertical component thrust and phugoid oscillation.

\section{Flightpath Angle Change Caused by Speed Stability}

The majority of airplanes, including the MD-11, exhibit positive speed stability. Over a short period (approximately $10 \mathrm{sec}$ ), a thrust increase will cause a speed increase. In turn, the speed increase causes a lift increase. When the lift becomes greater than the weight, the airplane will climb. The long-term effect is oscillatory. (See Phugoid subsection.)

\section{Pitching Moment Resulting from Thrust Line Offset}

If the engine thrust line does not pass through the vertical c.g., a pitching moment will be introduced by thrust change. For many transport aircraft, the thrust line is below the c.g., and increasing thrust results in a desirable nose-up pitching moment. For the MD-11 airplane, if the three engines are used equally, the 


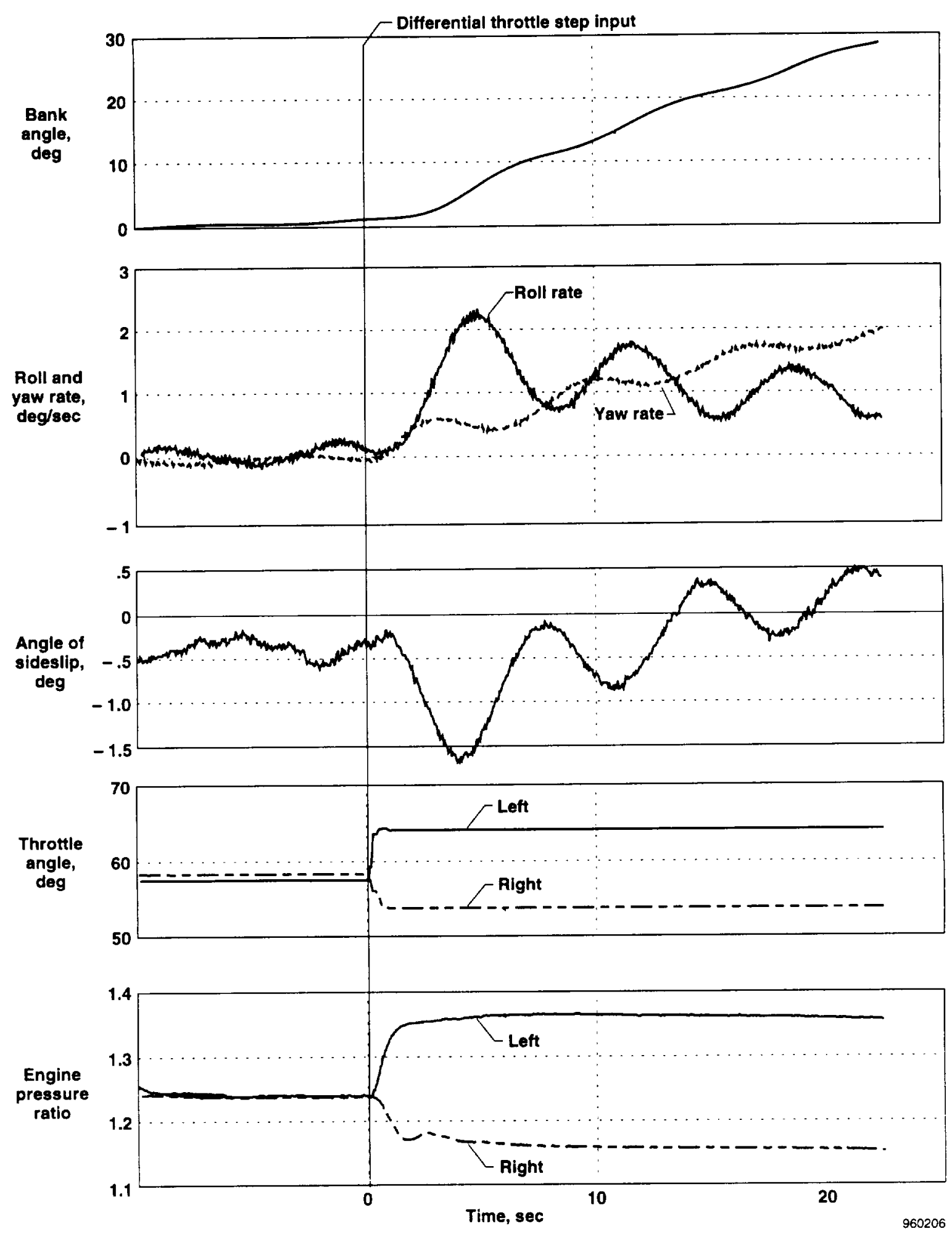

Figure 3. The MD-11 flight response to differential throttle step inputs, PCA off, $220 \mathrm{kn}$, flaps up, gear down, yaw dampers off, and center engine idle. 
resultant thrust line is near the vertical c.g., and this effect is small. The wing engines are $10 \mathrm{ft}$ below the vertical c.g. If only the wing engines are used, the noseup pitching moment is significant. The center engine of the MD-11 is $20 \mathrm{ft}$ above the vertical c.g. and causes a strong nosedown pitching moment with thrust increase.

\section{Elightpath Angle Change Because of the Vertical Component of Thrust}

If the thrust line is inclined to the flightpath, as is commonly the case, an increase in thrust will increase the vertical component of thrust, which will cause a vertical acceleration and a resulting increase in flightpath angle. For a given airplane configuration, this effect will increase as angle of attack increases.

For the MD-11 airplane, the combined short-term effect of a thrust increase is to produce a nose-up flightpath response. Figure 4 shows a time history of the step throttle increase of the wing engines at $220 \mathrm{kn}$. Thrust responds within approximately $1 \mathrm{sec}$. Pitch attitude and the resulting angle of attack increases approximately $0.3^{\circ}$, and airspeed increases for the first $10 \mathrm{sec}$.

When the wing-mounted engines are used for control, pitching moment because of thrust offset is the strongest component. In addition, a throttle advance increases pitch attitude and angle of attack such that the long-term effect is a climb at reduced trim airspeed. The converse is also true. A reduction in wing engine thrust causes a descent at increased speed.

\section{Phugoid}

The phugoid, or longitudinal long period oscillation of an airplane, may be excited by a pitch, thrust, or velocity change. For the MD-11 airplane, the phugoid is lightly damped. Figure 5 shows a flight example. This phugoid oscillation, with the same airplane configuration and flight conditions as those shown in figure 4 , was excited by a pullup which results in a lightly damped oscillatory climb. Note that the average trim airspeed is reduced from 220 to $210 \mathrm{kn}$, and the average angle of attack is increased and is out of phase with the airspeed. With throttles fixed, a slight oscillation in EPR occurred because of the changing flight conditions. Properly sized and timed throttle inputs can be used to damp unwanted phugoid oscillations. $^{2}$

\section{Relative Position of Inlet to Exhaust Nozzle}

The relative positions of the inlet and the exhaust nozzle of each engine may have an important effect for throttles-only flight control. The ram drag vector acts through the centroid of the inlet area, along the flightpath, and thus rotates with respect to the airplane geometric reference system as angles of attack and sideslip change. The gross thrust vector usually acts along the engine centerline and, thus, maintains its relationship to the airplane geometric reference system. Ram drag can be a significant percentage of gross thrust, particularly at low power settings where it may approach the magnitude of the gross thrust.

In the pitch axis, having the inlet located above the engine centerline is beneficial. An increase in throttle, which will increase ram drag and gross thrust, will result in a nose-up moment. This is the case for the B-2 airplane and for the center engines of the B-727 and L-1011 aircraft. If the inlet is located below the engine centerline, an increase in thrust causes an undesirable nosedown moment. The F-16 and F-18 aircraft are examples of such a configuration. Podded engines typically have the inlet and nozzle closely aligned, and a neutral effect results.

In the yaw axis, the principles are similar. The desirable geometry has the engine nozzles outboard of the inlets, so an increase in thrust would result in a favorable yawing moment. Unfortunately, this nozzle placement is not the case for many fighter airplanes that have the inlets outboard of the engines. For the MD-11 airplane, with podded engines, these inlet and nozzle effects are small.

\section{Trim Speed Control}

Once the normal flight control surfaces of an airplane are locked at a given position, the trim airspeed of the majority of airplanes is only slightly affected by engine thrust. In general, the speed will need to be reduced to an acceptable landing speed. This reduction requires developing nose-up pitching moments. Methods include moving the c.g. aft, lowering flaps, increasing the thrust of low-mounted engines, decreasing the thrust of highmounted engines, or burning off or dumping fuel. Extending the landing gear often decreases trim speed because it requires an increase in engine thrust.

On the MD-11 airplane, several ways to control trim speed exist. Flaps and stabilizer trim require hydraulic power which may not always be available. The center engine may be used as a moment-generating device to change angle of attack and, hence, to control the speed. Increasing center engine thrust has a strong nosedown pitch effect and increases the trim speed. Starting with all throttles equal, increasing thrust on the wing engines 


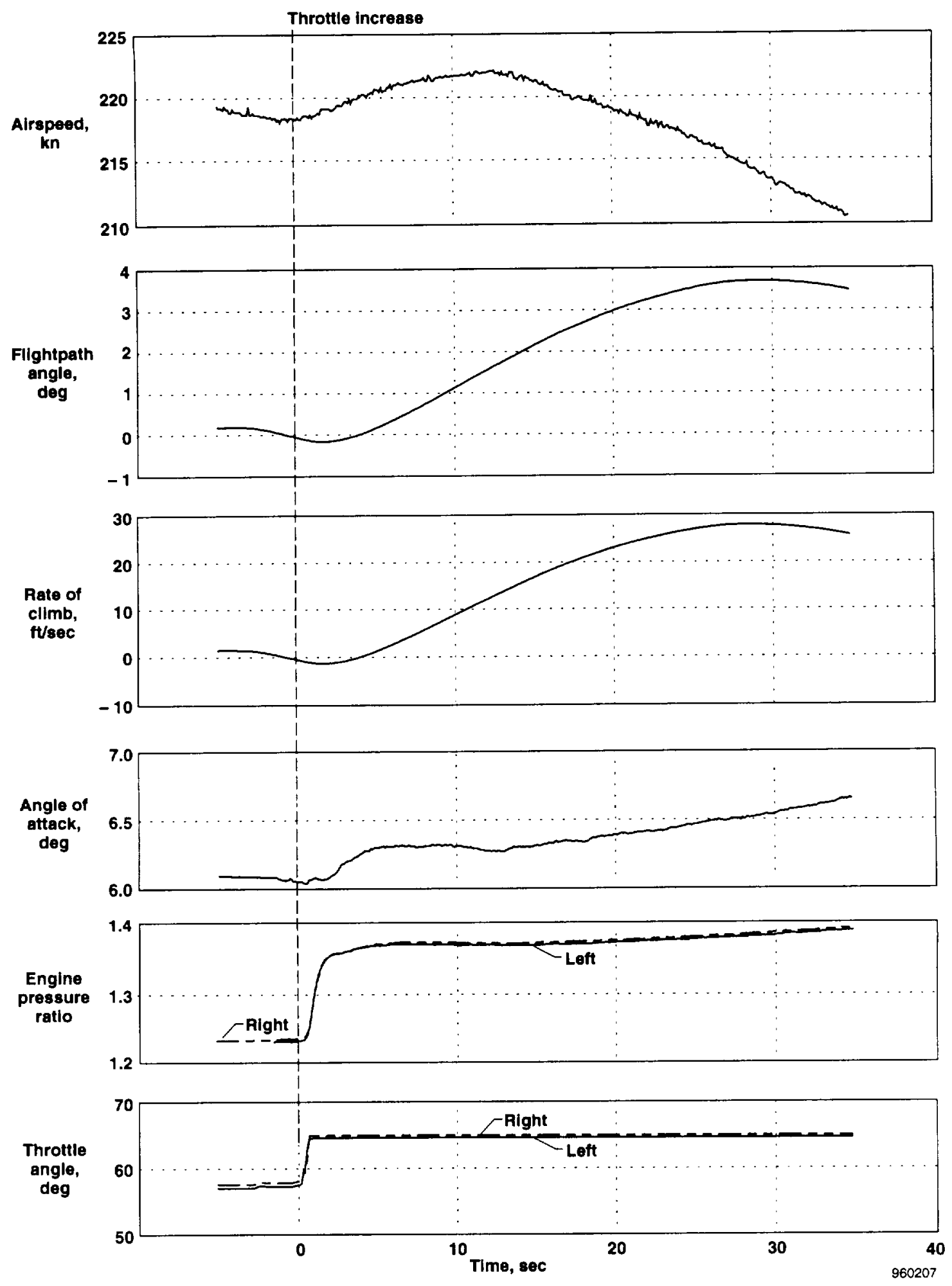

Figure 4. Flight response of MD-11 airplane to step throttle increase, PCA off, LSAS off, flaps up, gear down, and center engine idle. 

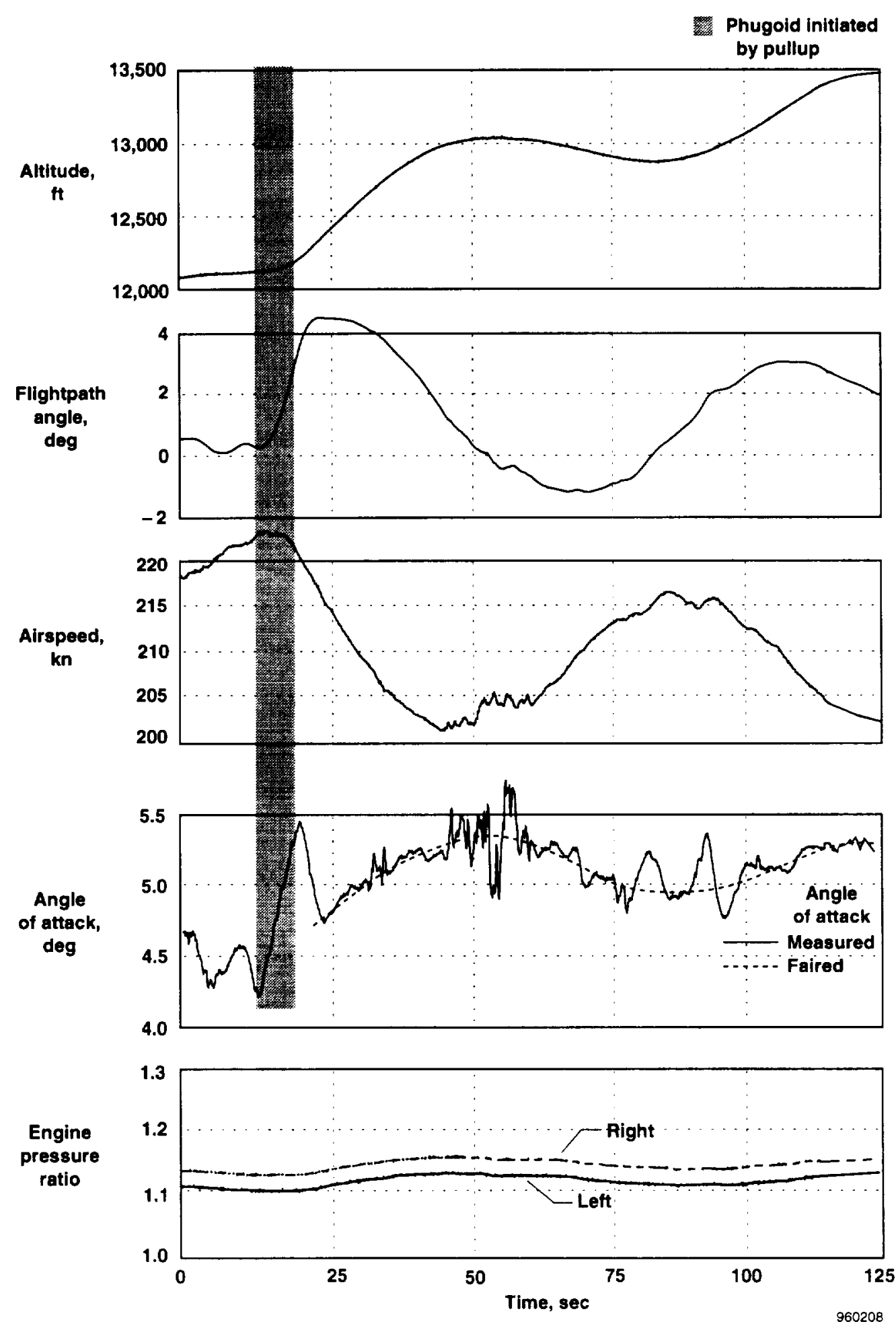

Figure 5. Time history of MD-11 phugoid, LSAS off, gear down, flaps up, light turbulence, fixed throttes, center engine idle, initiated by an elevator pull-up and release. 
and decreasing thrust on the tail engine to idle thrust reduces speed by 20 to $30 \mathrm{kn}$. Lowering the landing gear with the alternate gear extension system reduces speed an additional 15 to $17 \mathrm{kn}$ because of the increased thrust required for the wing engines to maintain level flight. This approach leaves the wells open and the landing gear doors exposed.

Trim speed is also affected by changes in weight. As weight is reduced (for example, by burning or dumping fuel), the lift remains constant, so the airplane tends to climb. It is assumed that the c.g. remains constant. To maintain level flight, the throttle setting must be reduced to reduce speed until lift and weight are again in balance. On the MD-11 airplane, flying at low speed, this effect reduces trim speed by approximately $1 \mathrm{kn}$ for every $3000 \mathrm{lb}$ of fuel consumed (approximately every $12 \mathrm{~min})$.

Figure 6 shows the MD-11 trim airspeed as a function of stabilizer setting and c.g. position. With these and other data over a range of GW obtained from the nonlinear simulation, determining the stabilizer-fixed speed range available as a function of GW and c.g. is possible. Fuel transfer either to or from the tail tank or between the main tanks provides speed change of up to $50 \mathrm{kn}$. Note that at the forward c.g., such as 12 percent, the airplane has strong speed stability (steep slope of stabilizer as a function of speed); whereas at aft c.g., such as 34 percent, speed stability is reduced by at least 50 percent.

\section{Speed Effects on Propulsive Control Power}

The propulsive forces (differential thrust for lateral control and collective thrust for flightpath control) tend to be relatively independent of speed. On the other hand, the aerodynamic restoring forces that resist the propulsive forces are proportional to the dynamic pressure, which is a function of speed squared. This relationship results in the propulsive control power being approximately inversely proportional to the square of the speed. ${ }^{2}$

\section{Surface Float with Hydraulics Turned Off}

When the hydraulic system fails, a surface will float to the zero hinge moment condition. For the MD-11 hinge geometry, this position is essentially the trail position. Simulator studies on the MD-11 airplane indicate that a total hydraulic failure would cause the ailerons to float with the trailing-edge up. The amount depends on speed, thus reducing lift and increasing trim airspeed. Rudder float would have a negligible effect on trim speed but would reduce directional stability. Elevators are usually trimmed to nearly zero force; hence, elevator float would have a small effect. The stabilizer is trimmed with a jackscrew actuator which, in case of

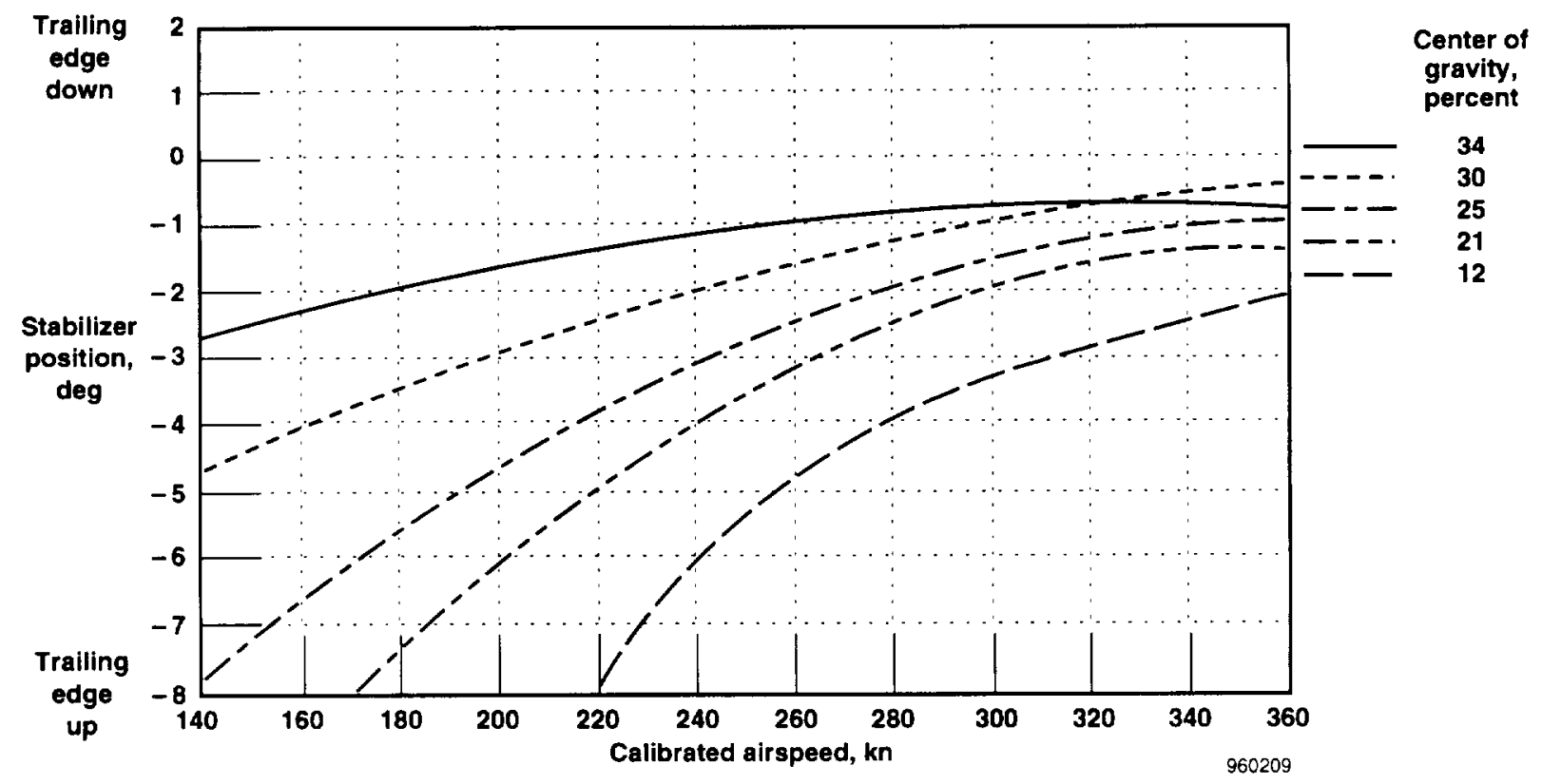

Figure 6. The MD-11 trim stabilizer position for a range of speed and c.g. positions, 560,000-lb GW, gear down, flaps up, 5000-ft altitude. 
hydraulic system failure, remains fixed because of friction.

\section{Throttles-Only Control Modes}

This section describes the two throttles-only control modes: manual throttles only and PCA control. These modes were tested in simulation and in-flight.

\section{Manual Throttles-Only Control}

For these tests, the crew turned off the LSAS, yaw dampers, speed protect system, and fuel transfer system; trimmed the airplane; released the flight controls; and used only the throttles for flight control. In this mode, the airplane behaved much like it would with a total flight control system failure. Then, pilots manually moved the throttles for control.

\section{Propulsion-Controlled Aircraft Control Logic}

In the PCA system, closed-loop control of engine thrust is provided to satisfy pilot-commanded flightpath and ground track. Figure 7 shows a simplified block diagram of the PCA control laws. For the two-engine PCA system, the center engine is used manually by the pilot as a low-frequency speed trimmer. The lateral axis shows only the track mode, but a bank angle control mode was also available.

In the lateral axis, differential thrust is controlled to provide precise track angle control (fig. 7(a)). The pilot's autopilot track knob command (selectable to integer degrees) is compared with the sensed track angle, generating a track error. This error is converted into a bank angle command and compared to the sensed bank angle, generating a bank angle error with the maximum bank angle limited to $\pm 20^{\circ}$. There is bank angle, yaw rate, and roll rate feedback for stabilization and dutch roll damping; differential thrust commands are issued to the wing engines to obtain the commanded track. Normal MD-11 bank angle limits could be selected on the heading or track knob, up to a limit of $\pm 20^{\circ}$. The pilot's track command is displayed by a bug on the compass and a vertical bar on the PFD (fig. 8) as well as on the ND cursor.

Longitudinal control is designed to provide precise flightpath control. In the pitch axis (fig. 7(b)), the pilot input through the autopilot thumbwheel command for flightpath angle is limited, compared to the sensed flightpath angle, and limited again. This command is selectable to a tenth of a degree. A low-gain integral path is provided in pitch to eliminate steady-state errors and pitch angle rate feedback to assist in phugoid damping. Collective (equal) thrust commands are sent to the wing engines to obtain the commanded flightpath. The thumbwheel flightpath command selected on the FCP is displayed to the pilot on the PFD using the existing fightpath command bar (fig. 8). The PCA flightpath commands were limited from $10^{\circ}$ to $-10^{\circ}$ and to errors to $\pm 3^{\circ}$.

Logic is provided to prevent the wing engines from being driven to very low power settings where the

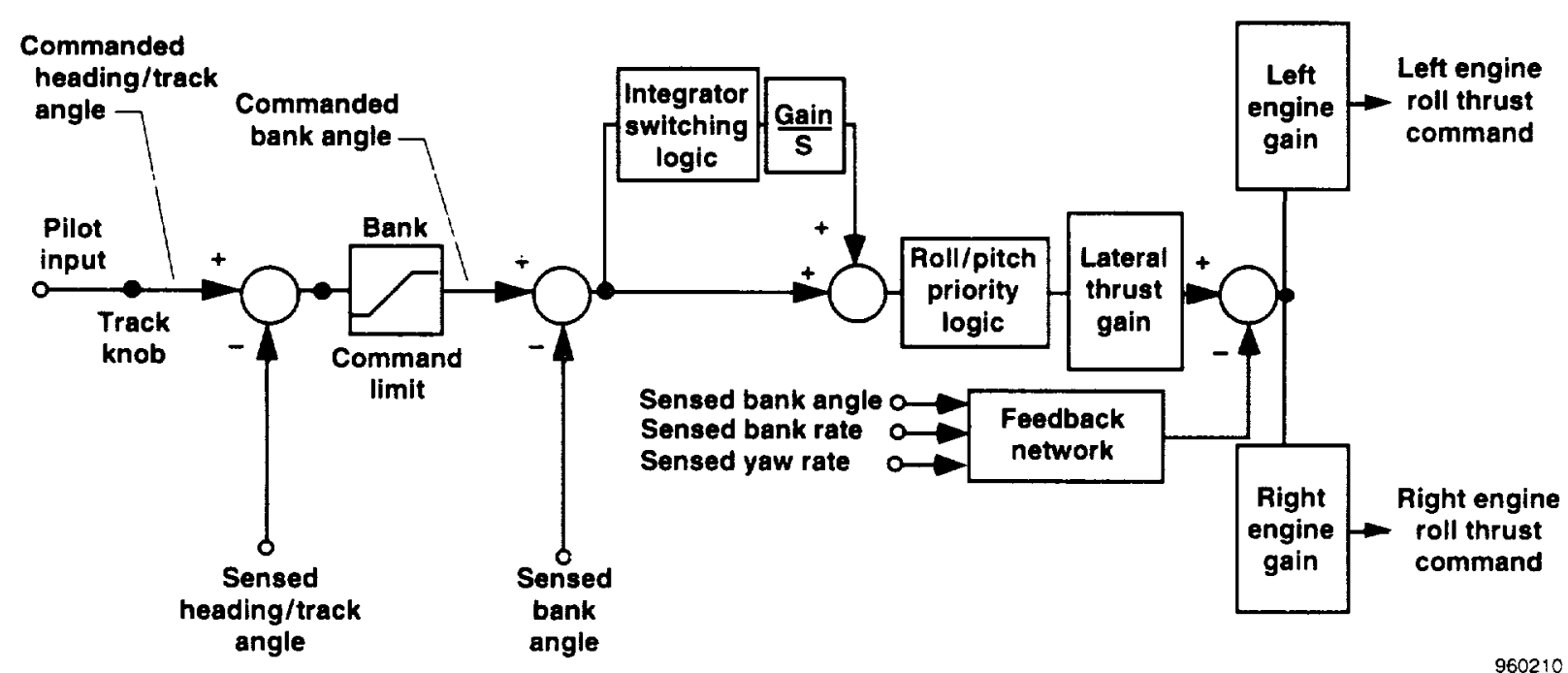

(a) Lateral controi system (track mode only).

Figure 7. The MD-1 I PCA block diagram (center engine speed control loop omitted). 


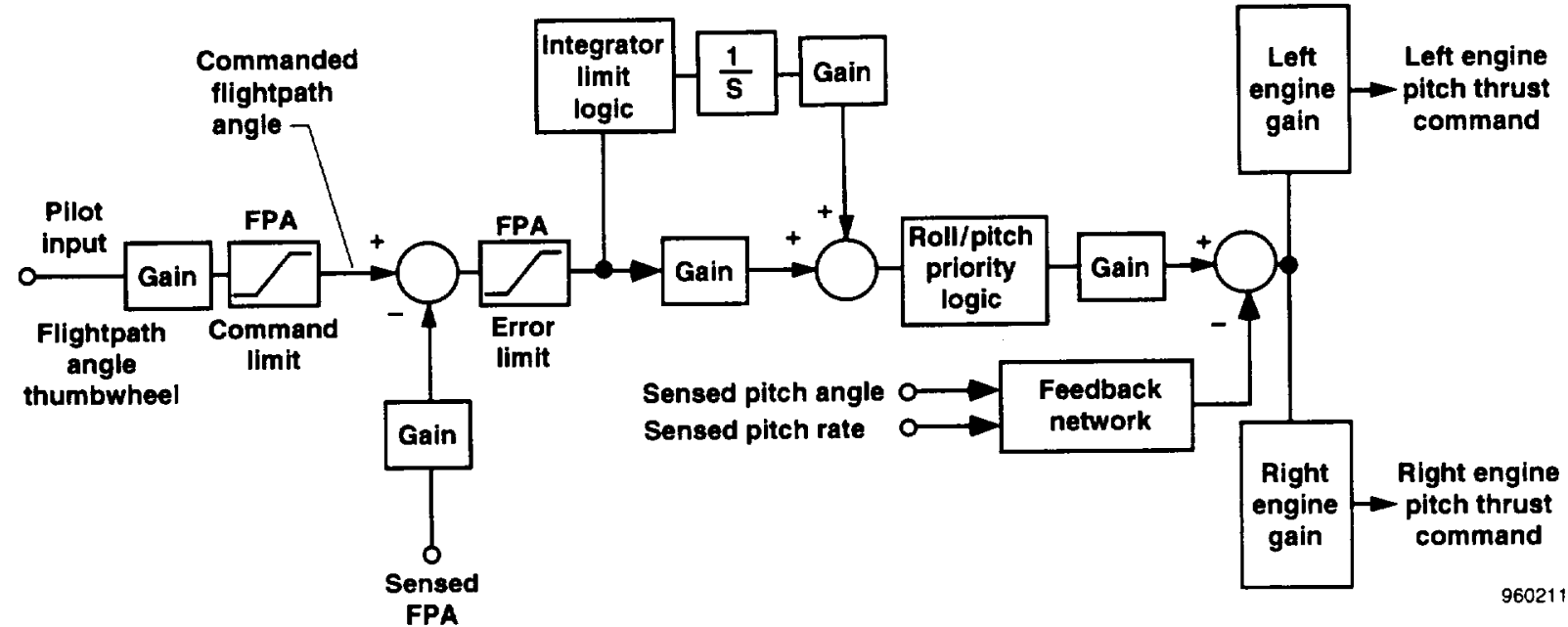

(b) Longitudinal control system.

Figure 7. Concluded.

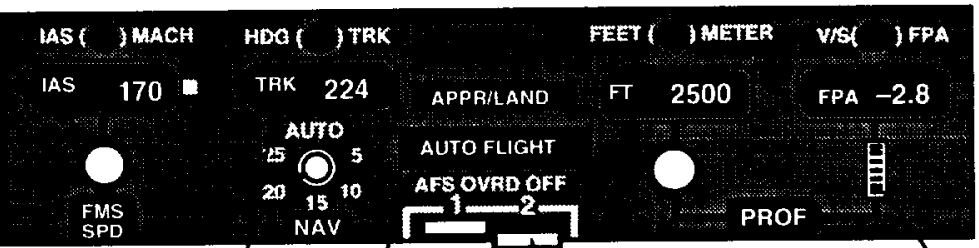

(2)

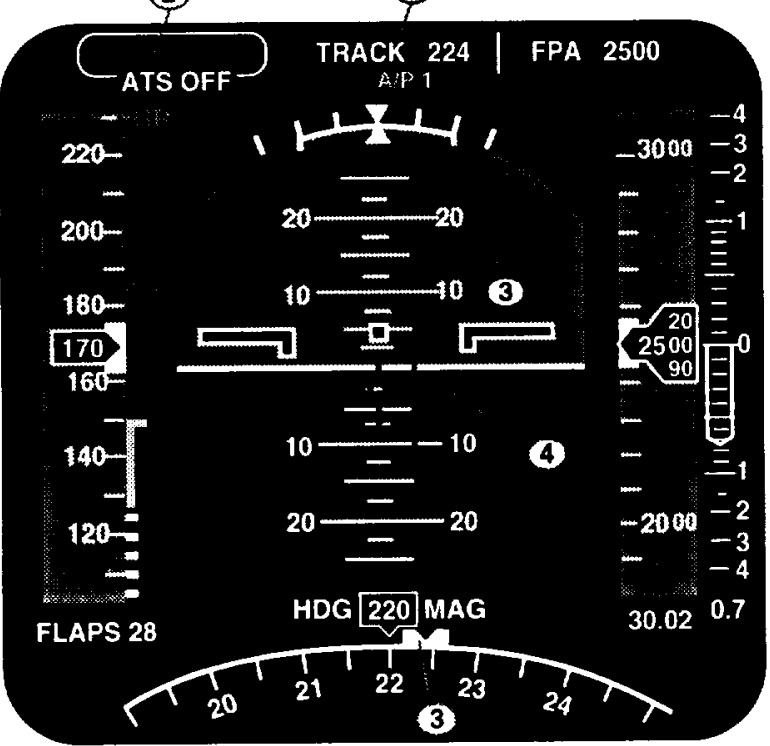

Primary flight display
(3)

(2)

Flight control panel (4)

(1) Number 2 AFS override paddle down to enable PCA (in FCC number 1)

(2) Autoflight pushed to engage PCA, see empty Speed window, AP1

(3) Heading or track button pushed to select track for lateral mode, turn knob to select, pull to engage, shown commanding $224^{\circ}$ track, track command shown as the vertical bars.

(4) V/S/FPA pushed to select the FPA vertical mode, to engage, move FPA thumbwheel command. Shown at $-2.8^{\circ}$.

Figure 8. Flight control panel and primary flight display showing PCA flightpath and track mode selection. 
engine response is very slow. In addition, integrator wind-up protection is provided. The priority logic also prevents saturation of pitch or roll commands.

Variable gains, filters, multipliers, gain schedules, and modes (selectable by the flight test engineer using the MCDU) were available at the majority of points within the PCA software, providing a great deal of flexibility for testing. More detailed design and analysis of the PCA control laws are discussed in reference 9. The speed control loop and augmented longitudinal control loop that uses the center engine is discussed in reference 10 .

\section{Implementation}

The PCA logic resides in one of the two FCC. The FCC provides a host of functions, including autopilot, autothrottle, navigation, and flight management system. Honeywell (Phoenix, Arizona) developed the code for the control laws, interfaced them to existing sensor signals, and sent commands to the engine FADEC computers over an ARINC 429 data bus.

Pratt \& Whitney modified the FADEC to accept a full-authority EPR command instead of the normal \pm 5 -percent EPR commands. For this initial flight test, a PCA disengage capability in case the throttles were moved was also incorporated. This capability instantly gives the pilots normal throttle control, if needed. The FCC 1 contained the PCA software; FCC 2 was unmodified. The PCA system implementation is discussed in detail in reference 11 .

\section{Operation}

The PCA system is activated by selecting FCC 1 and disabling FCC 2 by lowering the AFS override paddle switch, and pushing the autoflight button on the FCP (fig. 8). The PCA engagement is indicated by the AP 1 (autopilot 1) indication and the empty box on the PFD speed window. Longitudinal control is commanded through the FPA thumbwheel. Lateral control is effected through the track knob. In the track mode, turning the knob selects the track, and pulling the knob sends the command to the PCA software. The PCA system may be disconnected by several methods. Each is indicated by a red flashing box on the PFD and an aurally annunciated autopilot warning.

\section{Development}

The PCA system was developed over a period of 3 years, beginning with manual throttles-only tests in the FDS. Although very difficult at first, a rapid learning curve developed. With some experience and a very high workload, gross control could be achieved. That is, bank angle, heading, and flightpath could be controlled within a few degrees. Because of the low-mounted wing engines, a pilot using only the wing engines could simply increase thrust slightly to increase flightpath and reduce thrust slightly to decrease flightpath. Phugoid damping could also be achieved using this technique; for example, add thrust during the descent and reduce thrust during the climb. The center engine could be used as a trimming device to control speed. Increasing center engine thrust has a strong nosedown pitch effect and increases the trim speed.

Differential thrust was effective in inducing sideslip, which resulted in the aircraft rolling. At speeds in excess of $170 \mathrm{kn}$, the dutch roll mode was adequately damped. In addition, bank angle could be controlled reasonably well. Below $170 \mathrm{kn}$, dutch roll damping decreased, and bank angle control was difficult. At the lower speeds, using the throttles to attempt to damp the dutch roll was quite difficult. Although gross control was certainly possible and improved with practice; a manual throttlesonly landing on a runway was very difficult.

Based on the success of the F-15 PCA development and the gross control capability of manual throttlesonly-control in the FDS, MDA performed a study of a PCA system for the MD-11 airplane. A linear model based on the FDS was developed and used to design a PCA control law. This control law worked well on the linear simulation. When tried on the FDS, however, performance was poor. The problems were primarily caused by the nonlinear engine response characteristics. Later, a nonlinear model was developed for control law analysis and development. Initially, the center engine was used along with the wing engines; however, to simplify the initial control design, only the wing engines were used.

The PCA system design and development studies were conducted in 1993. The prime contractor, MDA, established subcontracts with Honeywell, Pratt \& Whitney, and General Electric (Evendale, Ohio). The preliminary design was completed in fall 1994. A test airplane with Pratt \& Whitney engines was selected, and the final design was complete in March 1995. MDA conducted integration tests in the bench simulation to verify proper communication over the data buses as well as proper engagement, annunciation, operation, and disengagement. " A ground test on the MD- 11 airplane verified end-to-end operation, including verification that PCA commands could be sent to the FADEC and that the engines would respond properly. 


\section{Flight Tests}

The PCA flight test program began by assessing the operational characteristics at $10,000 \mathrm{ft}$ in smooth air. The evaluation consisted of turning off the LSAS and yaw dampers, trimming the airplane, releasing the controls, and engaging the PCA system. Two configurations were tested: a clean condition at approximately $220 \mathrm{kn}$ and a takeoff configuration with $28^{\circ}$ flaps and gear extended at approximately $175 \mathrm{kn}$. At altitude, pitch and track control were good. The pilots were impressed that the PCA system performed almost as well as the normal autopilot. This system controlled flightpath to a few tenths of a degree. With a level flightpath command, the system also held altitude to within $\pm 20 \mathrm{ft}$.

Figure 9 shows a flight response to a series of flightpath steps and a comparison to the FDS. The pilot first selected a $-2^{\circ}$ flightpath step. Both engine EPR decreased sharply because of the flightpath error, then almost immediately began to increase because of the pitch rate feedback. The $2^{\circ}$ command was reached in approximately $7 \mathrm{sec}$, then overshot approximately 25 percent. Angle of attack followed EPR closely, and airspeed varied inversely as it did in the open-loop throttle steps. These FDS data show more angle-ofattack change and less flightpath overshoot than the flight data.

Lateral control was evaluated at $10,000 \mathrm{ft}$ with step inputs in track angle command. Track was controlled to within $1^{\circ}$. In addition, track captures showed no overshoot, but initial response was slow. Next, the PCA system was tested at $5000 \mathrm{ft}$. Then, the test included approaches to the runway in turbulent air.

Pitch control remained very good, track control was sluggish. On approaches it was difficult to anticipate the sluggish track response. Some gain changes improved the initial lateral control response. Data in reference 9 show the original and improved track response. The time for a $5^{\circ}$ track change was reduced from 22 to $17 \mathrm{sec}$; maximum bank angle increased from $4^{\circ}$ to $6^{\circ}$.

Figure 10 shows a time history of a large track command with the improved control gains and with the gear down and flaps at $28^{\circ}$. The pilot commanded a right $80^{\circ}$ turn; the engine differential thrust response resulted in a maximum roll rate of $3.5 \mathrm{deg} / \mathrm{sec}$. The $20^{\circ}$ bank limit was reached in approximately $10 \mathrm{sec}$. Flightpath angle dropped approximately $0.5^{\circ}$ but corrected back with a loss of only $30 \mathrm{ft}$. Once stabilized in the $20^{\circ}$ bank, the EPR increased from 1.20 to 1.25. Airspeed increased approximately $7 \mathrm{kn}$, and turn rate was approximately $4 \mathrm{deg} / \mathrm{sec}$. In the rollout, flightpath was again well controlled.

With the improved track response, approaches to the runway were made. After establishing the airplane configuration with the gear down, a takeoff flap setting of $28^{\circ}$, and the stabilizer trimmed for an approach speed of approximately $170 \mathrm{kn}$, the flight controls were released and not touched, thus simulating a flight control failure. The PCA system was activated. The pilots usually set the PCA flightpath command to the desired glideslope and then spent the majority of their attention making track corrections to achieve and maintain runway alignment. In the summer turbulence at Yuma, Arizona, on their first few approaches, judging the inputs required to maintain runway alignment was difficult.

The MD-11 airplane was flown to Edwards AFB, California, for initial PCA landings where there is a $15,000 \mathrm{ft}$ long and $300 \mathrm{ft}$ wide runway. Three PCA low approaches and go-arounds were flown. Continuous light turbulence existed, and occasional upsets from thermals occurred. However, PCA performance was judged adequate to proceed to PCA landings. On the first intended landing initial lineup and flightpath control was good (fig. 11). Based on simulation experience, the pilot selected a flightpath of $-1^{\circ}$ at $140 \mathrm{ft}$ above ground level (AGL). The flightpath overshot. Then at $30 \mathrm{ft}$ AGL, the sink rate was increasing to $8 \mathrm{ft} / \mathrm{sec}$, so the safety pilot, as briefed, made a small nose-up elevator input, then allowed the airplane to touch down under PCA control. The touchdown was $25 \mathrm{ft}$ left of the runway centerline and $5000 \mathrm{ft}$ from the threshold at a sink rate of $4.5 \mathrm{ft} / \mathrm{sec}$. The MD-11 airplane was stopped using reverse thrust and brakes, but spoilers or nosewheel steering were not used.

The second landing used a slightly different flightpath control technique. ${ }^{9}$ The PCA pilot made small track changes to maintain runway lineup and set the flightpath command at $-1.9^{\circ}$ for the initial part of the approach. Airspeed was $175 \mathrm{kn}$. At $200 \mathrm{ft}$ AGL, based on the experience with the first landing, the pilot shallowed the flightpath to $-1^{\circ}$ and at $100 \mathrm{ft}$ to $-0.5^{\circ}$. The airplane touched down smoothly on the centerline at a $4 \mathrm{ft} / \mathrm{sec}$ sink rate $3000 \mathrm{ft}$ from the threshold with no inputs from the safety pilot. The thermal updraft upset the airplane bank angle to $9^{\circ}$ at $100 \mathrm{ft}$ AGL; the PCA track mode corrected without pilot input. The airplane was stopped using reverse thrust and light braking, but no flight control inputs were required. 

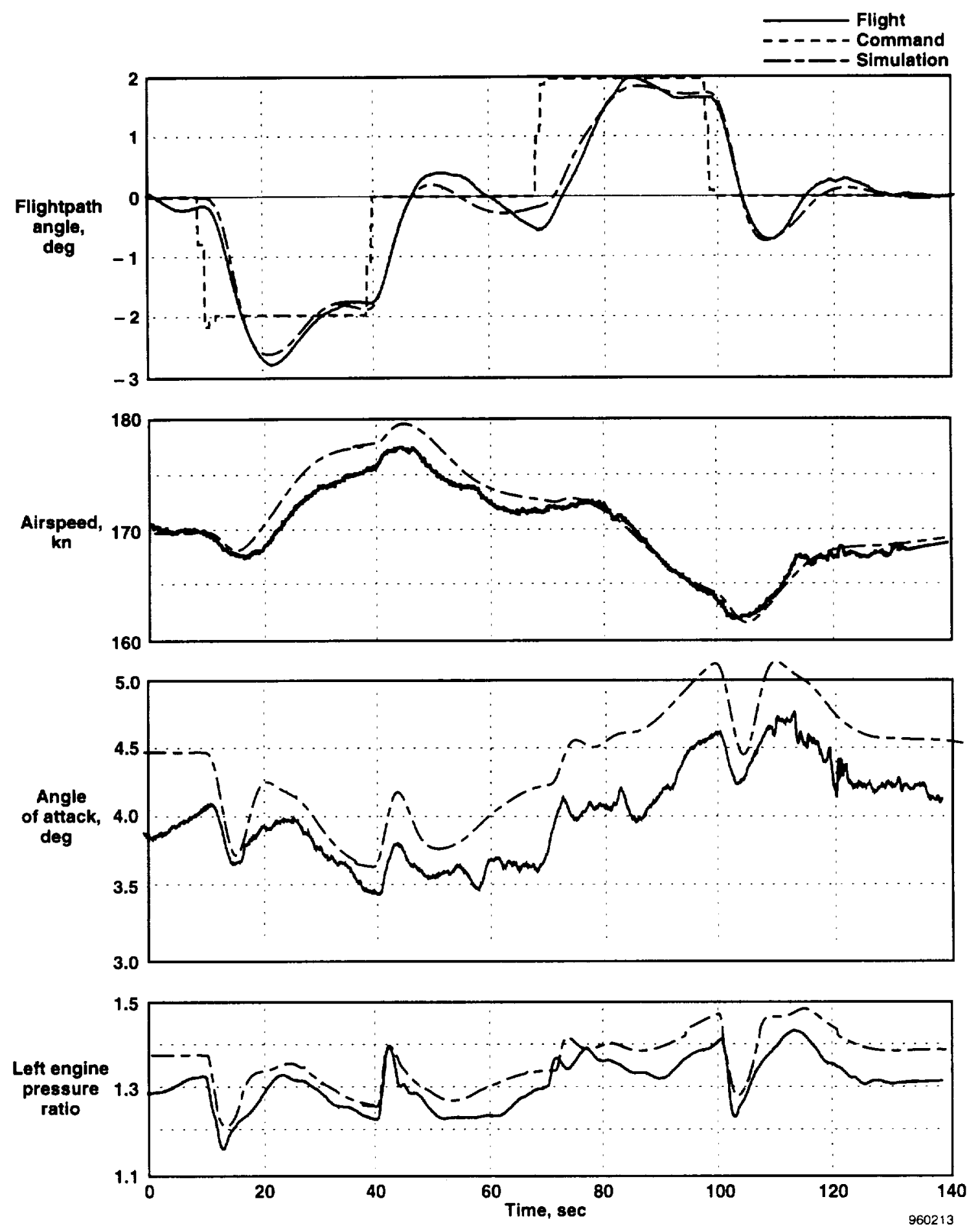

Figure 9. The PCA response to thumbwheel flightpath step commands, gear down, flaps $28^{\circ}$, flight and flight deck simulator, 10,000-ft altitude, and center engine idle. 


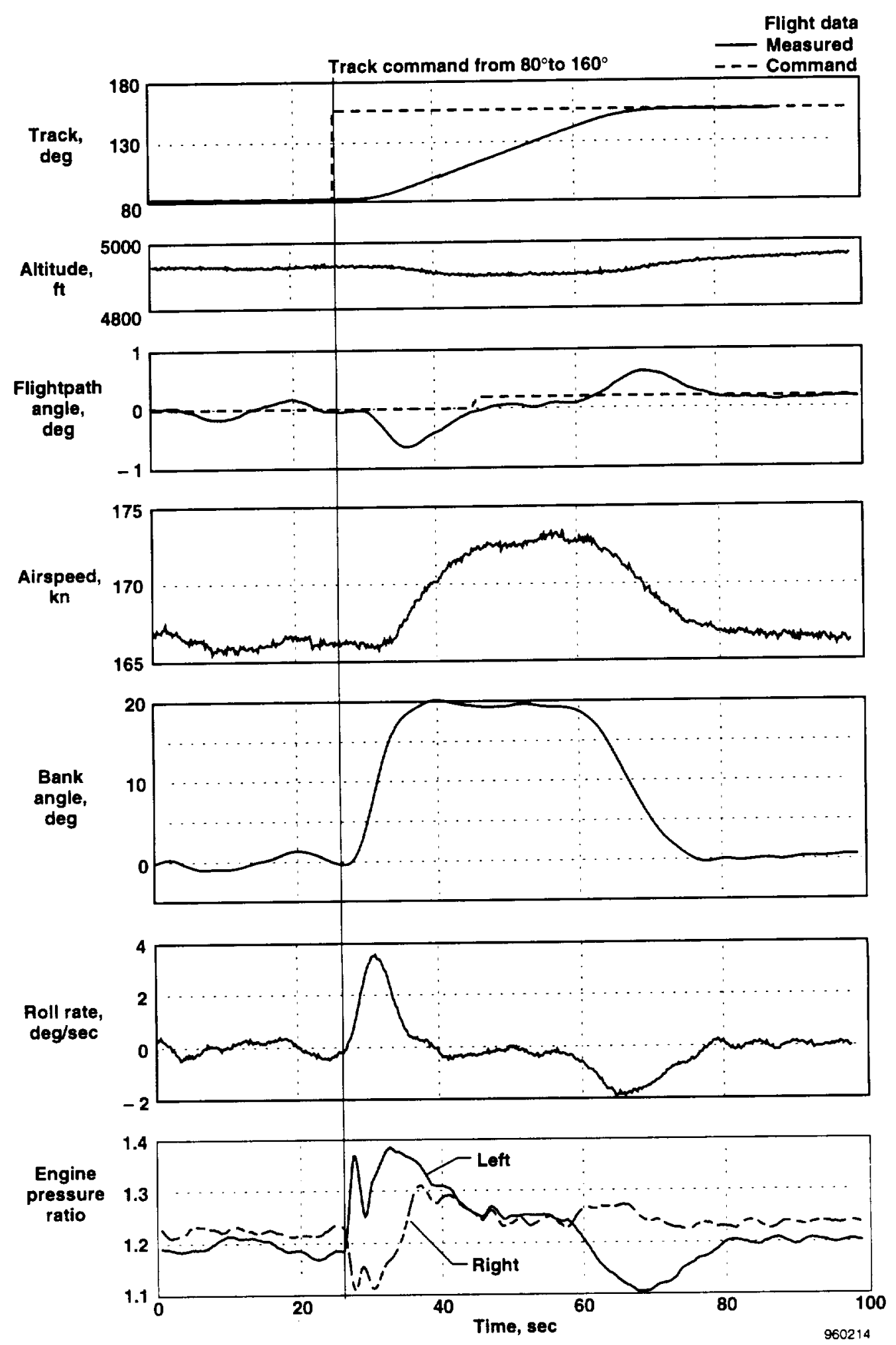

Figure 10. Time history of MD-11 PCA track change of $80^{\circ}$, gear down, $28^{\circ}$ flaps, and center engine idle. 


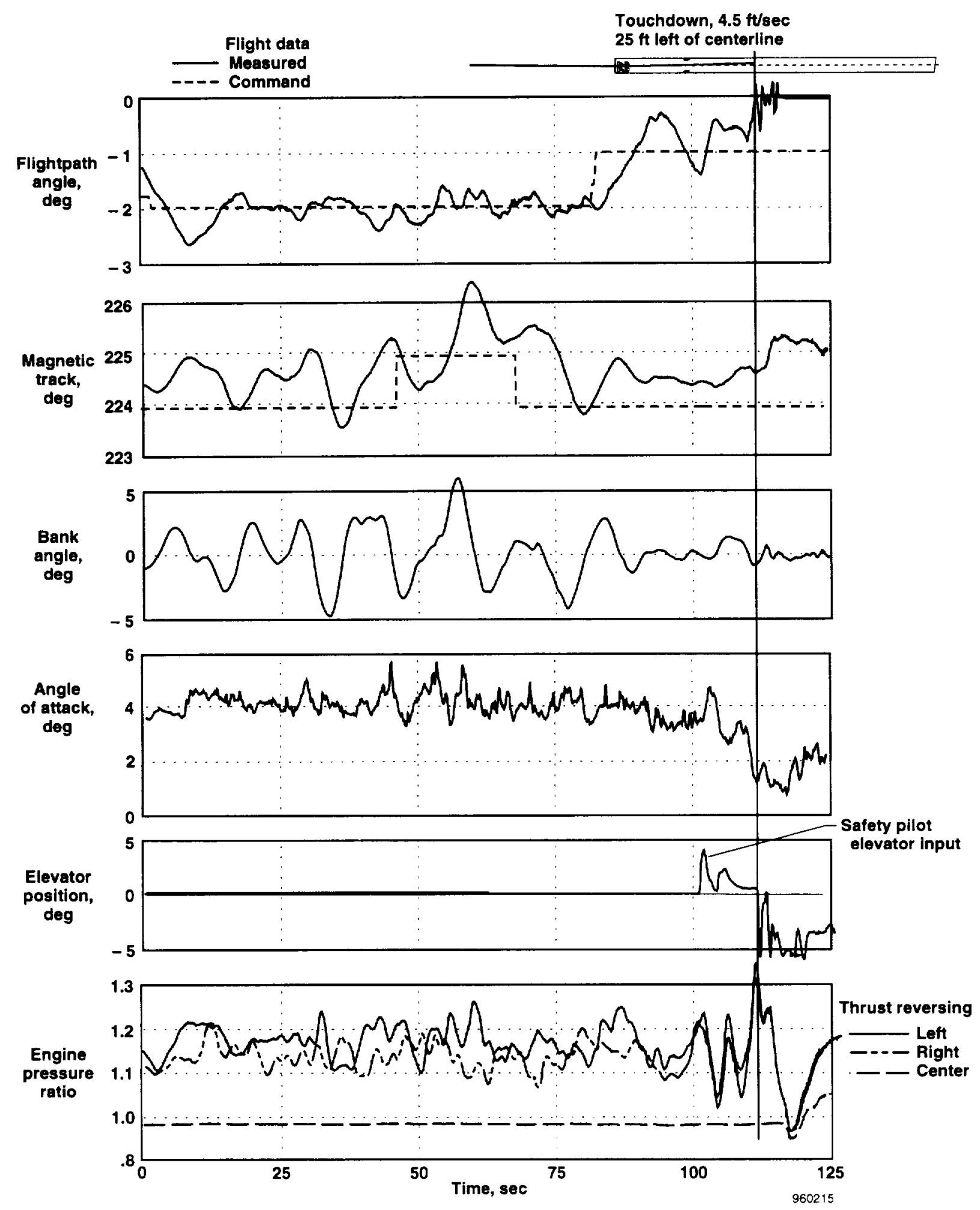

Figure 11. Time history of PCA landing, $28^{\circ}$ flaps, and $180 \mathrm{kn}$. 
From the two landings in light turbulence, it was observed that PCA generally controlled track and pitch to within $\pm 0.5^{\circ}$ of command (disregarding the $1^{\circ}$ bias in the track command). The EPR variations were normally approximately \pm 0.1 ; a $0.4 \mathrm{EPR}$ differential thrust was used to correct for the thermal upset. Ground effect was similar to that seen in the simulator.

The only significant problem encountered in PCA testing to this point was the sluggish and difficult to predict lateral control on approaches in turbulence. Pilots found that three or four approaches were required before adequate lineups were consistently achieved. Figure 12 shows the fourth approach of a PCA pilot, flown with a $1.5^{\circ}$ rudder offset to test the PCA system robustness. The approach was flown at Yuma, Arizona, and the pilot achieved runway lineup just inside 5 miles. Continuous light-to-moderate turbulence occurred because of thermal activity, but the pilot was still able to maintain adequate runway alignment and glideslope down to $200 \mathrm{ft}$ AGL. At this point, the planned PCA goaround was initiated. Go-around performance was good. Approximately $60 \mathrm{ft}$ were lost before achieving a positive rate of climb. Note the $\pm 2-\mathrm{kn}$ airspeed changes from the turbulence, the increased average airspeed of almost $10 \mathrm{kn}$ on the glideslope, and the extensive EPR activity to maintain control in the turbulence.

\section{Envelope Expansion}

Following successful completion of the PCA landings, it was decided to test PCA operation beyond the original design envelope. Figure 13 summarizes the MD-11 design and flight test envelope. Based on simulation results, PCA performance was expected to degrade as altitude increased because of reduced engine response and degrading dutch roll characteristics. The PCA was tested at middle and aft c.g., at altitudes from 200 to $30,000 \mathrm{ft}$ mean sea level, at speeds from 160 to $360 \mathrm{kn}$, with a $1.5^{\circ}$ rudder offset, with a $7^{\circ}$ aileron offset, and with the hydraulics turned off. Approaches were flown with a takeoff flaps setting of $28^{\circ}$, with slatsonly, and without flaps or slats. The center engine was used for speed control. The PCA engagement in mild upset conditions was tested.

The third FADEC was installed on the center engine, providing a low-frequency speed control. It worked very well; trim speed could be changed $30 \mathrm{kn}$ above and below the initial trim speed. Pitch control was maintained within $1^{\circ} .^{10}$

The PCA system tests were conducted at 15,000, 20,000 , and $30,000 \mathrm{ft}$. Contrary to predictions from the simulation, operation was good; pitch control was essentially unchanged at these altitudes. Lateral control was stable as well.

For aft c.g., at $30,000 \mathrm{ft}$, the c.g. was shifted from 24 to 32 percent, and step response tests were conducted. Response was good. The PCA system was tested at maximum airspeeds of $360 \mathrm{kn}$ and Mach 0.83 with no degradation in performance.

The ability to recover from upsets was tested. With the PCA system turned off, the airplane was upset using the normal controls. When the desired conditions were achieved, the pilot released the controls and activated the PCA system. All recoveries were successful; the most severe recovery occurred from a $45^{\circ}$ bank and a $7^{\circ}$ dive. When engaged, the PCA logic tries to hold the commanded flightpath and track at the time of engagement. In the upsets, the track deviates several degrees during the recovery, so after flightpath has been stabilized, the airplane returned to the reference track command.

Figure 14 shows a time history of tests in which all three hydraulic systems were turned off. Before the time shown, all hydraulic systems were turned off for several minutes. The outboard ailerons had floated to $12^{\circ}$, and the inboard ailerons had floated to $5^{\circ}$. Meanwhile, the elevators had floated near zero. Contrary to simulation results, the floating surfaces resulted in a nose-up pitch and caused a reduced trim speed. It was planned to lower the landing gear, which was expected to lower the trim speed further.

Because airspeed was already near the minimum speed for flaps-up flight, the hydraulic system 3 was turned on as shown. The ailerons returned to the trim position, causing a pitchdown. Then, the stabilizer was retrimmed to an increased speed position. When the system 3 hydraulics were again turned off, the ailerons again floated up, and the pitchup again occurred. The PCA system reduced the throttles to idle to reestablish commanded flightpath, and speed stabilized at $212 \mathrm{kn}$. After a small track change, the landing gear was lowered using the alternate gear extension system. With the gear doors down and the wheel wells remaining open, speed decreased to $195 \mathrm{kn}$. Note that lowering the gear moved the aileron and elevator slightly. The hydraulic pressure was zero, but of course there was still fluid in the system.

The PCA maintained flightpath well in this transient. Track and pitch control at this point were normal and identical to that with the hydraulics systems turned on. 


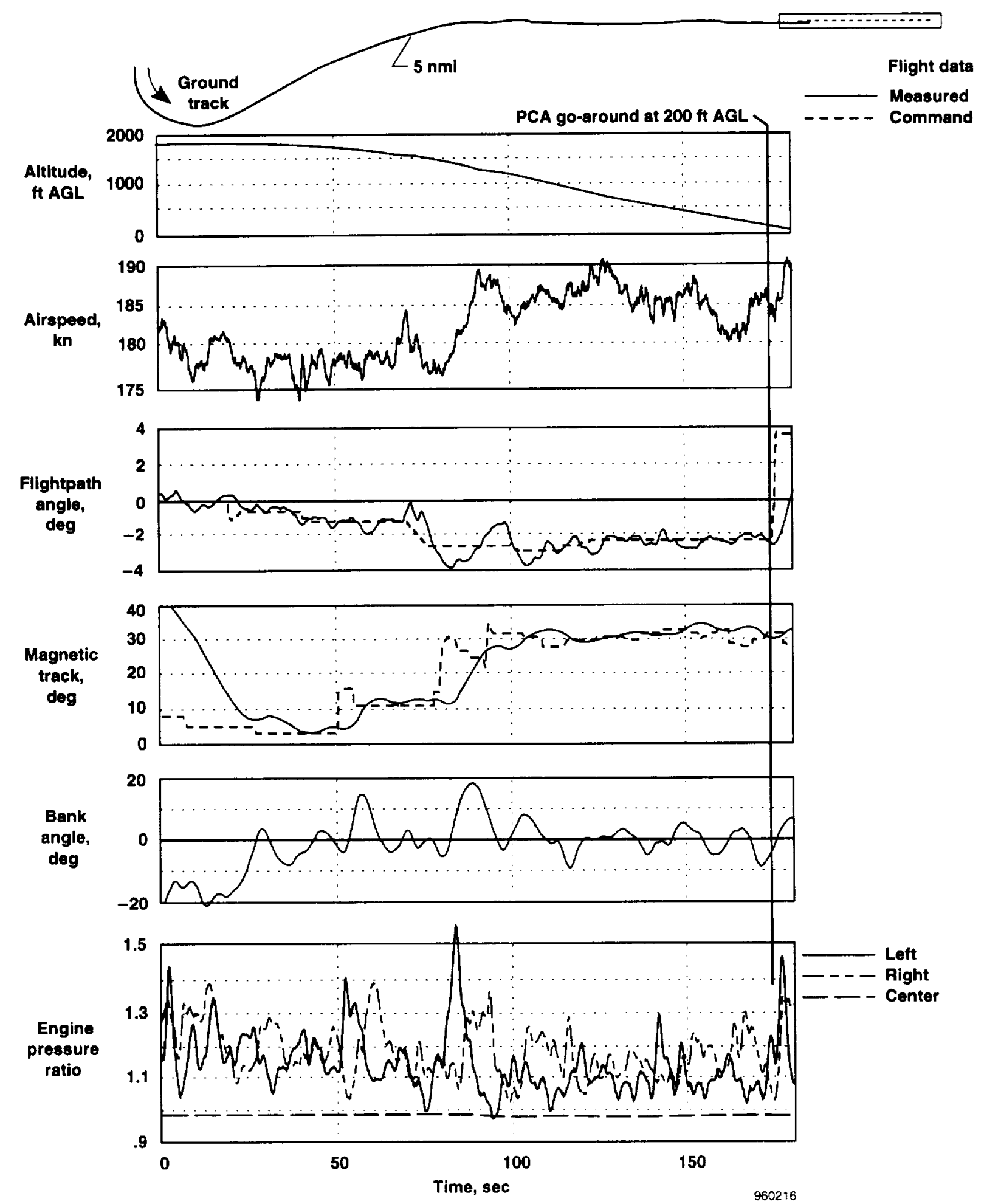

Figure 12. The MD-11 PCA system approach and go-around with $1.5^{\circ}$ rudder offset, gear down, $28^{\circ}$ flaps, continuous light-to-moderate turbulence and thermal upsets. This was the pilot's fourth PCA approach. 


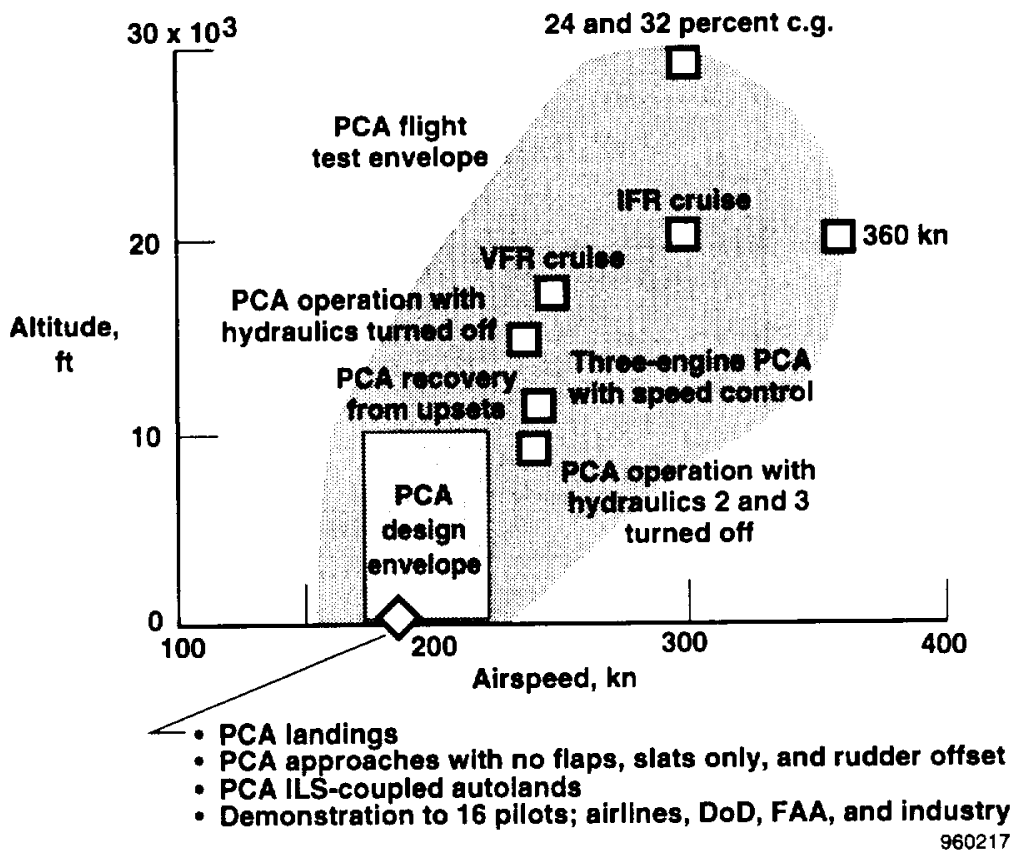

Figure 13. The MD-11 PCA design and flight test envelope. 


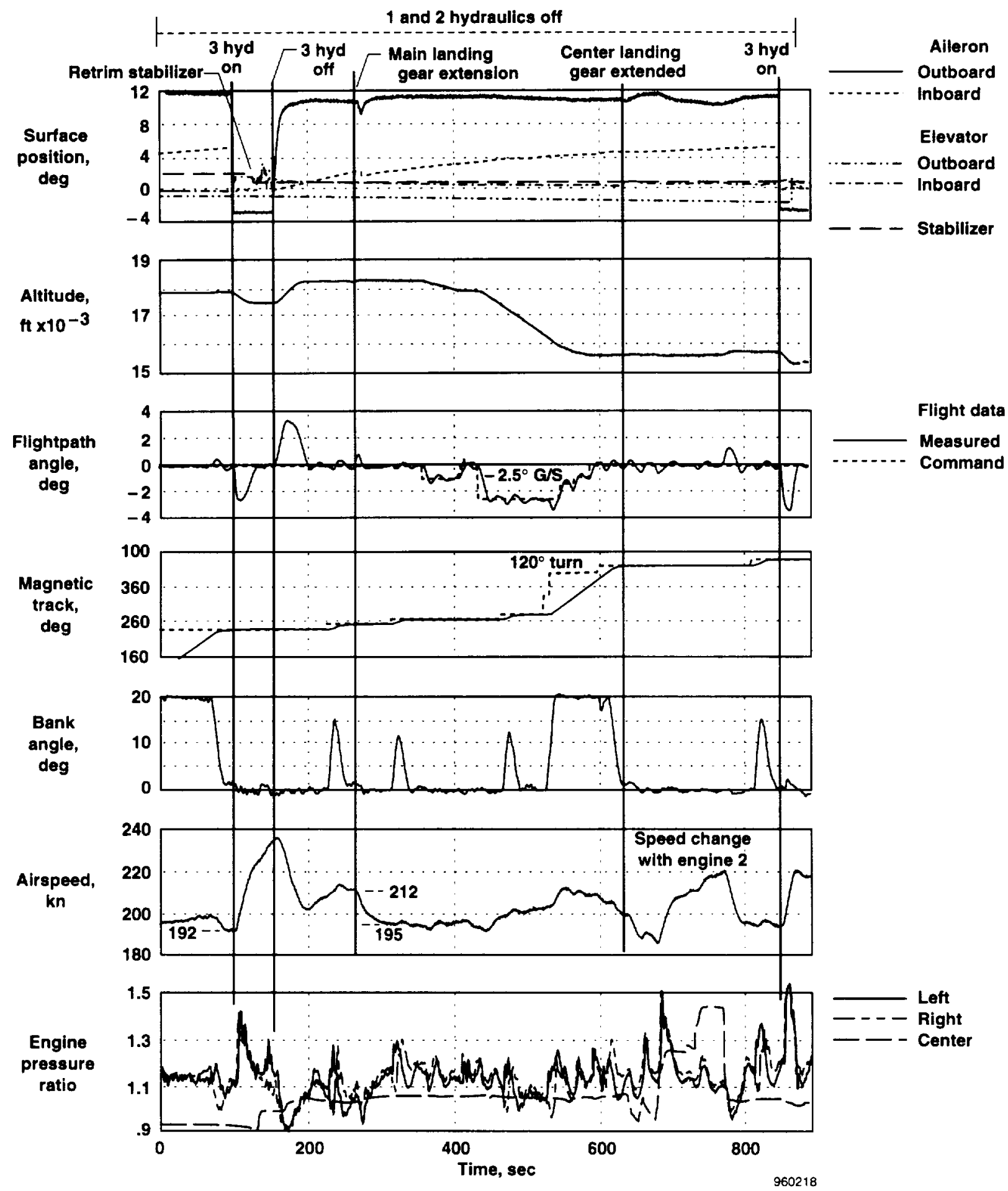

Figure 14. Time history of MD-11 PCA operation with hydraulic systems turned off. 
A simulated landing approach was made using a $-2.5^{\circ}$ glideslope with a small track change. A large track change was commanded at $560 \mathrm{sec}$. Bank angle stabilized at its $20^{\circ} \mathrm{limit}$, and flightpath was stepped back to level flight. The center main landing gear was then extended, resulting in another small change in surface positions. The PCA control remained normal. Hydraulics systems were then turned back on still under PCA control.

The PCA operation as an autopilot was sufficiently good that at times, PCA remained engaged for $1 \mathrm{hr}$ or more. Overall in the $30 \mathrm{hr}$ flight program, over $25 \mathrm{hr}$ of PCA operation were logged. No unplanned PCA disengagements occurred.

\section{Simulation-To-Flight Comparison}

The flight test results generally compared well with the flight deck simulation. The pitch control in-flight is somewhat less damped than in the simulator, possibly because the vertical c.g. in the test airplane is lower than in the simulation. The somewhat difficult lateral control effects on approach were well-modeled. Anticipated lateral control instability at high altitudes, based on simulation, were not found in-flight. The trim speed change caused by turning off the hydraulics systems was the right magnitude but the wrong sign.

\section{Pilot Comments}

Pilot comments were recorded on the cockpit video immediately after each approach. The project pilot reported that pitch control was excellent and that all of the workload was in the lateral task. In turbulent air, anticipating the lead needed for track changes was difficult. In addition, getting established on centerline well out and using only small inputs was necessary. After the PCA landings, the project pilot was really impressed that control was so good and commented that not only a survivable landing but a normal landing could be made using PCA control. Other pilots also found that the lateral control was sufficiently sluggish that considerable practice was needed to learn how to maintain runway lineup.

\section{Instrument Landing System-Coupled Approach}

It was obvious that the lateral control was sufficiently sluggish that a pilot could not be assured of making a successful approach on the first try with a significant level of turbulence. An ILS-coupled PCA mode had been checked out on the PCA simulation at DFRC and $\mathrm{ARC}^{7}$ and had worked very well. As a result, the ILScoupled mode was incorporated into the MD-11 PCA system. This modification was accomplished by Honeywell. Existing MD-11 ILS-coupled logic and displays were used as much as possible. Because this modification was for concept demonstration only, no attempt was to be made to optimize the ILS-coupled system. Requirements were to capture the ILS localizer first within a $30^{\circ}$ intercept. The glide slope was to be captured from below. The glideslope to be flown was adjustable from 0.5 to 1.5 dots below the glideslope. (One dot is $0.35^{\circ}$.) A simple two-step autoflare capability was also added. All ILS approaches were successful, including two actual hands-off landings.

Figure 15 shows a time history of an ILS-coupled landing. Before the time shown, the pilot had selected a track to intercept the localizer in level flight approximately 12 miles from the runway and pressed the approach-and-landing (appr/land) button (fig. 8) to arm the ILS capture. At localizer capture, the system rolled the MD-11 airplane onto the localizer with one overshoot and maintained a slight descent rate until glideslope capture at 10 miles out. The glideslope capture resulted in an overshoot. Once established on the ILS, localizer tracking was excellent, and glideslope tracking was adequate. The preprogrammed flares at 130 and $30 \mathrm{ft}$, arrested the sink rate and resulted in a touchdown $1 \mathrm{ft}$ from the centerline, at $5 \mathrm{ft} / \mathrm{sec}$ sink rate, and at a point $1200 \mathrm{ft}$ beyond the threshold. After touchdown, the PCA system was deactivated by moving the throttles to idle. The nose lowered, and the nosewheel touched down smoothly. The pilot used differential braking to slow and maintain directional control. Another ILS-coupled landing was made with a touchdown sink rate of less than $2 \mathrm{ft} / \mathrm{sec}$ and on the centerline. 9

These ILS-coupled approaches and landings were made under nearly ideal weather conditions, but simulator and computer analysis showed that safe landings could be made in turbulence levels up to moderate conditions. The ability of the coupled system to make small thrust changes to correct a deviation immediately provided a major improvement in capability over pilot-in-the-loop control as well as a huge reduction in pilot workload.

\section{Demonstration Flights}

The PCA system was demonstrated to 16 pilots representing airlines, U.S. Air Force, U.S. Navy, industry, and Federal Aviation Administration. After a simulator session, each pilot flew manual throttles-only control, then flew with the PCA system using the FCP knobs. Each also made an approach to a virtual runway 


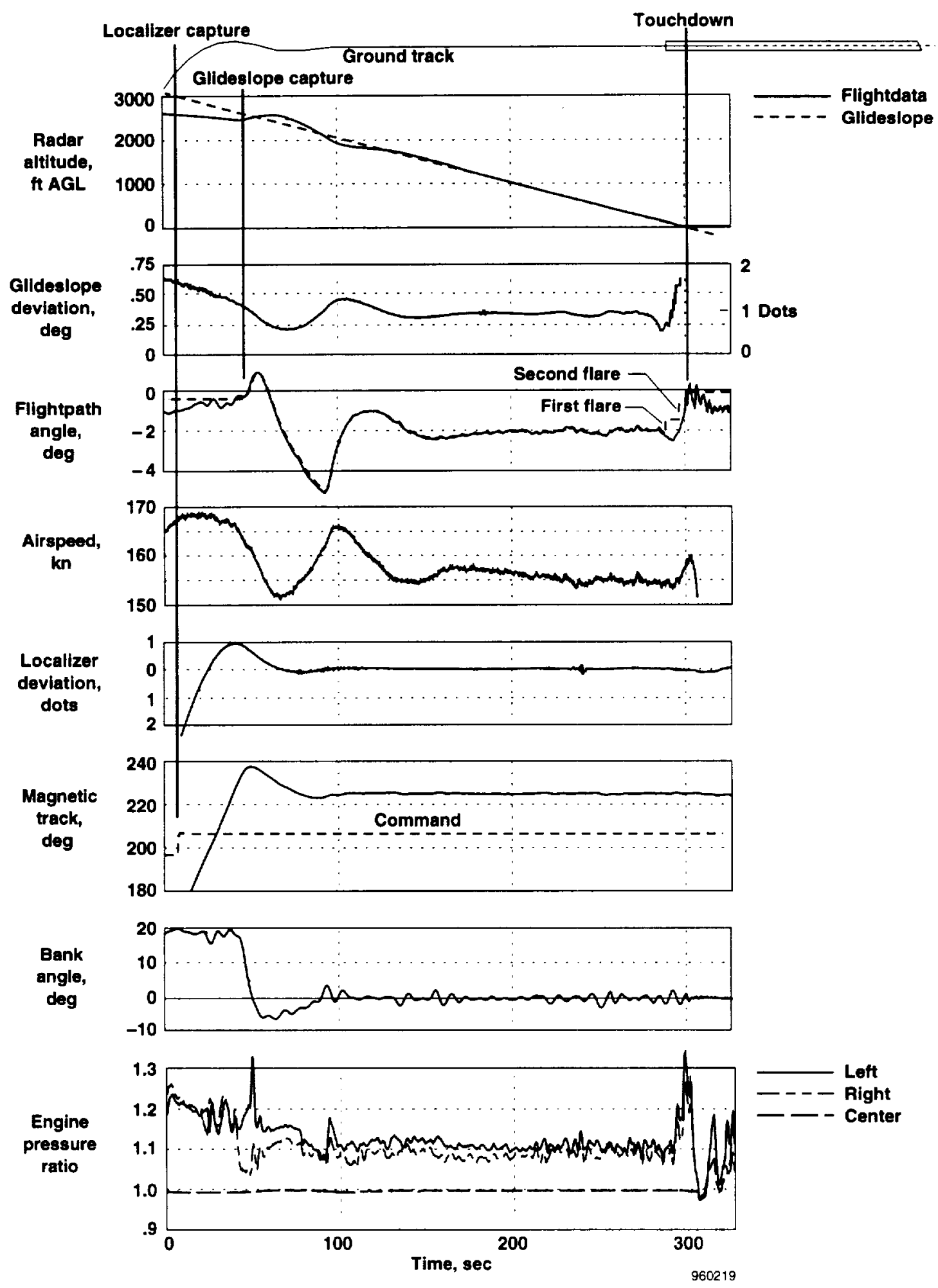

Figure 15. Time history of PCA ILS-coupled approach and hands-off landing, $28^{\circ}$ flaps. 
$100 \mathrm{ft}$ AGL. The majority of pilots used the ILS-coupled mode. A few used PCA flightpath and track control. In the very smooth air, even the PCA approaches using the FCP knobs were successful. All pilots were positively impressed with the PCA system.

\section{Future Applications}

Based on the success of these MD-11 airplane and previous F-15 PCA flight tests, a PCA system appears to provide an acceptable backup flight control system capable of safe landings independent of hydraulic power. The addition of a slow electric actuator for trimming the stabilizer for trim speed control would eliminate the need to plan and use c.g. and weight control for controlling speed.

\section{Concluding Remarks}

A Propulsion-Controlled Aircraft (PCA) system using closed-loop thrust for control has been designed, developed, and tested on an MD-11 airplane. This system was implemented with software changes to existing flight and engine control computers and uses the autopilot knobs on the glareshield flight control panel. Flight tests demonstrated that PCA can successfully provide control adequate for up-and-away flight and for runway landings. The PCA instrument landing system-coupled mode was used to make handsoff landings. The PCA system was tested over a wide flight envelope and found to perform somewhat better than predicted. Flight-to-simulation comparisons were generally reasonably good. Sixteen demonstration pilots flew the PCA system, and pilot comments were very favorable.

\section{$\underline{\text { References }}$}

'Frank W. Burcham, Jr., Trindel Maine, C. Gordon Fullerton, and L. Dean Webb, Development and Flight Evaluation of an Emergency Digital Flight Control System Using Only Engine Thrust on an F-15 Airplane, NASA TP-3627, 1996.

${ }^{2}$ Burcham, Frank W., Jr., and C. Gordon Fullerton, Controlling Crippled Aircraft - With Throttles, NASA TM-104238, 1991.
${ }^{3}$ Gilyard, Glenn B., Joseph L. Conley, Jeanette L. Le, and Frank W. Burcham, Jr., "A Simulation Evaluation of a Four-Engine Jet Transport Using Engine Thrust Modulation for Flightpath Control," AIAA 91-2223, June 1991. (See also NASA TM-4324, 1991.)

${ }^{4}$ Burcham, Frank W., Jr., Trindel Maine, and Thomas Wolf, Flight Testing and Simulation of an F-15 Airplane Using Throttles for Flight Control, NASA TM-104255, 1992.

5Propulsion Controlled Aircraft, NASA TM-104278, 1995. (See also internet address: http://www.dfrc.nasa. gov/dryden/html.)

${ }^{6}$ Gerren, Donna S., Design, Analysis and Control of a Large Transport Aircraft Using Selective Engine Thrust as a Back-up for the Primary Flight Control, NASA CR-186035, 1995.

${ }^{7}$ Bull, John, et al., Piloted Simulation Tests of Propulsion Control as Backup for Loss of Primary Flight Controls for a Mid-Size Jet Transport, NASA TM-110374, 1995.

${ }^{8}$ Dornheim, Michael A., "Throttles Land "Disabled" Jet", Aviation Week and Space Technology, Sept. 4 , 1995, p.p. 26-27.

${ }^{9}$ Burken, J., J. Feather, S. Goldthorpe, J. Kahler, T. Maine, and F.W. Burcham, "Flight Test of a Propulsion-Based Emergency Control System on the MD-11 Airplane," AIAA 96-3919, July 1996.

${ }^{10}$ Burken, John, et al., "Longitudinal Emergency Control System Using Thrust Modulation (MD-11)," AIAA 96-3062, July 1996.

${ }^{1}$ Feather, J.B. and F.W. Burcham, Jr., Development and Flight Test of a Propulsion Controlled Aircraft (PCA) System and Application to the MD-11 Airplane. MDC 96-K0202, McDonnell Douglas Aerospace, Long Beach, California, March 1996. 
Public reporting burden for this collection of information is estimated to average 1 hour per response, including the lime for reviewing instructions, searching existing data sources. gathering and maintaining the data needed, and completing and reviewing the collection of information. Send comments regarding this burden estimate or any other aspect of this collection of intormation. including sugestions for reducing this burden, to Washington Headquarters Services, Directorate for Intormation Operations and Reports, 1215 Jefierson Davis Highway, Suite 1204, Arlington. VA 22202-4302, and to the Office of Management and Budget, Paperwork Reduction Project (0704-0188), Washington. DC 20503.

\begin{tabular}{|l|l|l}
\hline 1. AGENCY USE ONLY (Leave blank) & $\begin{array}{c}\text { 2. REPOAT DATE } \\
\text { July } 1996\end{array}$ & $\begin{array}{c}\text { 3. REPORT TYPE AND DATES COVERED } \\
\text { Technical Memorandum }\end{array}$ \\
\hline
\end{tabular}

4. TITLE AND SUBTITLE

Development and Flight Test of an Augmented Thrust-Only

Flight Control System on an MD-11 Transport Airplane
WU 505-68-10

\section{AUTHOR(S)}

Frank W. Burcham, Jr., Trindel A. Maine, John J. Burken, and Drew Pappas

\section{PERFORMING ORGANIZATION NAME(S) AND ADDRESS(ES)}

NASA Dryden Flight Research Center

P.O. Box 273

Edwards, California 93523-0273

\section{FUNDING NUMBERS}

Edwards, California $93523-0273$

9. SPONSORING/MONOTORING AGENCY NAME(S) AND ADDRESS(ES)

National Aeronautics and Space Administration

Washington, DC 20546-0001

NASA TM-4745

\section{SUPPLEMENTARY NOTES}

Presented as AIAA 96-3742, AIAA Guidance, Navigation, and Control Conference, San Diego, California, July $29-31,1996$. F.W. Burcham, Jr., T.A. Maine, and J.J. Burken, NASA Dryden Flight Research Center, Edwards. California. Pappas, McDonnell Douglas Aerospace, Long Beach, California.

\begin{tabular}{|l|l|}
\hline 12a. DISTRIBUTIONAAVALABILTY STATEMENT & 12b. DISTRIBUTION CODE \\
Unclassified_Unlimited & \\
Subject Category 08 & \\
\hline 13. AESTRACT (Maximum 200 words) & \\
\hline
\end{tabular}

13. ABSTRACT (Maximum 200 words)

An emergency flight control system using only engine thrust, called Propulsion-Controlled Aircraft (PCA), has been developed and flight tested on an MD-11 airplane. In this thrust-only control system, pilot flightpath and track commands and aircraft feedback parameters are used to control the throttles. The PCA system was installed on the MD-11 airplane using software modifications to existing computers. Flight test results show that the PCA system can be used to fly to an airport and safely land a transport airplane with an inoperative flight control system. In up-and-away operation, the PCA system served as an acceptable autopilot capable of extended flight over a range of speeds and altitudes. The PCA approaches, go-arounds, and three landings without the use of any normal flight controls have been demonstrated, including instrument landing systemcoupled hands-off landings. The PCA operation was used to recover from an upset condition. In addition, PCA was tested at altitude with all three hydraulic systems turned off. This paper reviews the principles of throttlesonly flight control; describes the MD-11 airplane and systems; and discusses PCA system development, operation, flight testing, and pilot comments.

\begin{tabular}{|c|c|c|c|}
\hline \multirow{2}{*}{\multicolumn{3}{|c|}{$\begin{array}{l}\text { 14. SUBJECT TERMS } \\
\text { Emergency flight control; MD-11 airplane; Propulsion-controlled aircraft; } \\
\text { Propulsive control; Throttle-only control }\end{array}$}} & \multirow{2}{*}{\begin{tabular}{|l|} 
15. NUMBER OF PAGES \\
28 \\
16. PRICE CODE \\
AO3 3 \\
\end{tabular}} \\
\hline & & & \\
\hline $\begin{array}{l}\text { 17. SECURITY CLASSIFICATION } \\
\text { OF REPORT }\end{array}$ & $\begin{array}{l}\text { 18. SECURITY CLASSIFICATION } \\
\text { OF THIS PAGE }\end{array}$ & $\begin{array}{l}\text { 19. SECUFITY CLASSIFICATION } \\
\text { OF ABSTRACT }\end{array}$ & 20. LIMITATION OF ABSTRACT \\
\hline Unclassified & Unclassified & Unclassified & Unlimited \\
\hline
\end{tabular}



National Aeronautics and

Space Administration

Code JTT

Washington, D.C. 20546-0001

USA

Official Business

Penalty for Private Use, $\$ 300$
SPECIAL FOURTH-CLASS RATE POSTAGE AND FEES PAID NASA PERMIT No G27

POSTMASTER: If Undeliverable (Section 158

Postal manual) Do Not Return 